\title{
A Critical Role for Dopamine D5 Receptors in Pain Chronicity in Male Mice
}

\author{
[DSalim Megat, ${ }^{1}$ SStephanie Shiers, ${ }^{1}$ ㄴ) Jamie K. Moy, ${ }^{1}$ 'Paulino Barragan-Iglesias, ${ }^{1}$ Grishma Pradhan, ${ }^{1}$ \\ - Rebecca P. Seal, ${ }^{2}$ Gregory Dussor, ${ }^{1}$ and ${ }^{\text {DTheodore J. Price }}{ }^{1}$ \\ ${ }^{1}$ University of Texas at Dallas, School of Behavioral and Brain Sciences, Richardson, Texas 75080, and 2Departments of Neurobiology and Otolaryngology, \\ Pittsburgh Center for Pain Research, University of Pittsburgh School of Medicine, Pittsburgh, Pennsylvania 16206
}

Dopaminergic modulation of spinal cord plasticity has long been recognized, but circuits affected by this system and the precise receptor subtypes involved in this modulation have not been defined. Dopaminergic modulation from the A11 nucleus of the hypothalamus contributes to plasticity in a model of chronic pain called hyperalgesic priming. Here we tested the hypothesis that the key receptor subtype mediating this effect is the D5 receptor (D5R). We find that a spinally directed lesion of dopaminergic neurons reverses hyperalgesic priming in both sexes and that a D1/D5 antagonist transiently inhibits neuropathic pain. We used mice lacking D5Rs (DRD5KO mice) to show that carrageenan, interleukin 6 , as well as BDNF-induced hyperalgesia and priming are reduced specifically in male mice. These male DRD5KO mice also show reduced formalin pain responses and decreased heat pain. To characterize the subtypes of dorsal horn neurons engaged by dopamine signaling in the hyperalgesic priming model, we used c-fos labeling. We find that a mixed D1/D5 agonist given spinally to primed mice activates a subset of neurons in lamina III and IV of the dorsal horn that coexpress PAX2, a transcription factor for GABAergic interneurons. In line with this, we show that gabazine, a GABA-A receptor antagonist, is antihyperalgesic in primed mice exposed to spinal administration of a D1/D5 agonist. Therefore, the D5R, in males, and the D1R, in females, exert a powerful influence over spinal cord circuitry in pathological pain likely via modulation of deep dorsal horn GABAergic neurons.

Key words: A11 nucleus; D5 receptor; descending modulation; dopamine; hyperalgesic priming; sex differences

\section{Significance Statement}

Pain is the most prominent reason why people seek medical attention, and chronic pain incidence worldwide has been estimated to be as high as $33 \%$. This study provides new insight into how descending dopamine controls pathological pain states. Our work demonstrates that dopaminergic spinal projections are necessary for the maintenance of a chronic pain state in both sexes; however, D5 receptors seem to play a critical role in males whereas females rely more heavily on D1 receptors, an effect that could be explained by sexual dimorphisms in receptor expression levels. Collectively, our work provides new insights into how the dopaminergic system interacts with spinal circuits to promote pain plasticity.

\section{Introduction}

Three major descending neuromodulatory systems that include noradrenergic projections (NE) from the locus ceruleus, serotoninergic (5-HT) projections from the nucleus raphe magnus, and dopaminergic (DA) projections from the hypothalamic A11

\footnotetext{
Received July 26, 2017; revised Nov. 8, 2017; accepted Nov. 10, 2017.

Author contributions: S.M., J.K.M., R.P.S., G.D., and T.J.P. designed research; S.M., S.S., J.K.M., P.B.-I., and G.P. performed research; S.M., S.S., and T.J.P. analyzed data; S.M., R.P.S., G.D., and T.J.P. wrote the paper.

This work was supported by National Institutes of Health Grant R01NS065926 to T.J.P., Grant R01GM102575 to T.J.P. and G.D., and Grant R01NS073664 to T.J.P., University of Texas STARS Program to T.J.P. and G.D., and postdoctoral CONACYT fellowship program to P.B.I.

The authors declare no competing financial interests.

Correspondence should be addressed to Dr. Theodore J. Price, University of Texas at Dallas, School of Behavioral and Brain Sciences, 800 West Campbell Road, BSB 14.102G, Richardson, TX 75080. E-mail: Theodore.price@utdallas.edu.

DOI:10.1523/JNEUROSCI.2110-17.2017

Copyright $\odot 2018$ the authors $\quad 0270-6474 / 18 / 380379-19 \$ 15.00 / 0$
}

nucleus are known to modulate the processing of nociceptive inputs and circuits in the spinal dorsal horn. Chemical lesions of these systems can change the response of spinal nociceptive circuits to inflammation or nerve injury (Ossipov et al., 2010). DA neurons are known to play a critical role in pain modulation in several areas of the CNS, including the anterior cingulate cortex (López-Avila et al., 2004), nucleus accumbens (Chang et al., 2014), and the spinal cord (Yang et al., 2005; Wei et al., 2009). DA projections to the spinal cord arise exclusively from the A11 area of the hypothalamus (Skagerberg and Lindvall, 1985), and these neurons modulate nociceptive processing via activation of postsynaptic DA receptors in the dorsal horn (Charbit et al., 2009, 2011; Wei et al., 2009; Taniguchi et al., 2011).

D1-like receptors (D1LR), including D1R and D5R, activate heterotrimeric proteins containing $\mathrm{G} \alpha$ s and are coupled to activation of adenylyl cyclase, whereas the D2-like subfamily (D2LR, 
D2R-D4R) are linked to activation of G $\alpha$ i and $\mathrm{G} \alpha$ o proteins (Neve et al., 2004; Beaulieu and Gainetdinov, 2011). All five receptors have been found to be expressed in the dorsal horn and/or DRG neurons (Dubois et al., 1986; Schambra et al., 1994; Yokoyama et al., 1994; Levant and McCarson, 2001; Zhao et al., 2007; Zhu et al., 2008). D1R expression is restricted to specific regions from lamina I to II, whereas D5Rs are widely expressed throughout the dorsal and ventral horn of the spinal cord (www.gensat.org) (Zhu et al., 2008). Selective ligands for D1Rs and D5Rs have not been described; therefore, genetic tools are required to define the open question of the respective roles of D1Rs and D5Rs in pain signaling.

We have recently shown that D1LRs, but not D2LRs, play an essential role in hyperalgesic priming (J. Y. Kim et al., 2015) and that these receptors are likely stimulated by the DA A11 projection from the hypothalamus in this context. Previous work has demonstrated that spinal DA receptors contribute to synaptic plasticity wherein D1LR agonism produces LTP of C-fiber-evoked field potentials (Yang et al., 2005). More recent findings indicate that, after spinal nerve ligation, D1LR stimulation induces a desensitization of spinal $\mu$ opioid receptors, via the release of met-enkephalin, leading to a loss of opioid-mediated inhibitory control in the spinal cord (Aira et al., 2016a). D1LR stimulation in the dorsal horn also induces phosphorylation of the NMDAR subunit NR1 (Aira et al., 2016b). Collectively, these studies point to a role of D1LRs in amplification of pain signaling in the dorsal horn of the spinal cord, but the receptor subtypes and cell specificity of these effects have not been delineated. Interestingly, DA neurons can synthesize and corelease GABA by using nonconventional GABAsynthesizing enzymes (J. I. Kim et al., 2015), and striatal DA synapses are frequently composed of contacts formed between dopaminergic presynaptic structures and GABAergic postsynaptic structures that express neuroligin-2 (Zhou et al., 2013). Increased neuroligin-2 expression has been implicated in two different models of chronic pain (Dolique et al., 2013; J. Y. Kim et al., 2016), but a link between DA and GABAergic spinal cord neurons has not been established.

Here we describe a previously unknown role for D5Rs in pathological pain. We show that genetic ablation of the D5R reduces acute pain responses and prevents hyperalgesic priming in male but not female mice. We also provide evidence of a link between descending DA neurons and the recruitment of spinal GABAergic neurons in pathological pain. Our work further establishes the role of DA in modulation of chronic pain via a spinal mechanism of action with a strong sexual dimorphism.

\section{Materials and Methods}

Experimental animals

All procedures that involve the use of animals were approved by the Institutional Animal Care and Use Committee of the University of Texas at Dallas and were in accordance with the International Association for the Study of Pain guidelines. All behavioral studies were conducted using male or female C57BL/6J mice weighing between 20 and $25 \mathrm{~g}$. Mice were used in behavioral experiments starting 1 week after arrival at the animal facility at the University of Texas at Dallas or were bred in that facility. Animals were housed with a $12 \mathrm{~h}$ light/dark cycle and had food and water available ad libitum.

\section{Dopamine receptor 5 knock-out mice (DRD5KO) and other} genetically modified mice

The dopamine receptor $5 \mathrm{KO}$ (Drd5) was generated as described previously (Hollon et al., 2002). This strain has a neomycin resistance gene and a proximal linker containing a stop codon, which were ligated in reverse orientation into a unique SfiI site within the dopamine receptor 5 gene (Drd5). This disrupts the reading frame within the coding region. Mice were genotyped upon weaning, and homozygous mutants or wild-
Table 1. Experimental drugs used in the study

\begin{tabular}{llll}
\hline Compound & Vendor & Catalog no. & Dose \\
\hline Rc human IL-6 & R\&D Systems & 26-IL-010 & $0.1 \mathrm{ng}$ in 25 $\mu \mathrm{l}$ \\
Rchuman BDNF & R\&D Systems & $248-B D-00 S$ & $00.1 \mathrm{ng}$ in $5 \mu \mathrm{l}$ \\
Carrageenan & Sigma-Aldrich & $\mathrm{C} 1013$ & $1 \%(\mathrm{w} / \mathrm{v})$ \\
6-OHDA hydrobromide & Sigma-Aldrich & $\mathrm{H} 116$ & $50 \mu \mathrm{g}$ \\
PGE $_{2}$ & Cayman Chemicals & 14010 & $100 \mathrm{ng}$ in 25 $\mu \mathrm{l}$ \\
SKF83958 & Sigma-Aldrich & $\mathrm{C} 130$ & $4.1 \mu \mathrm{g}$ \\
SCH23390 & Tocris Bioscience & 0925 & $3.3 \mu \mathrm{g}$ \\
Gabazine & Tocris Bioscience & 1262 & $150 \mu \mathrm{g}$ \\
\hline
\end{tabular}

type were identified using 3 sets of primers: D1B1, 5'-ACT CTC TTA ATC GTC TGG ACC TTG-3'; D1B2, 5'-GGA GGA GAT ACG GCG GAT CTG AAC-3'; and D1B3, 5' -TGA TCA ACT AGT GCC CGG GCG GTA-3'. All reactions were performed using RED TaqDNA polymerase (Sigma-Aldrich) and run on a Bio-Rad thermocycler. The PCR products were analyzed on a $3 \%$ agarose gel with Gel Green and imaged using a ChemiDoc MP imager. The DRD5KO mice develop normally with no notable differences from wild-type littermates with respect to appearance, body weight, or home cage behaviors. DAT ${ }^{\text {IREScre }}$ animals were generated as described previously (Bäckman et al., 2006) and crossed to ROSA-LSL-tdTomato mice.

\section{Neuronal lesions}

Spinal DA lesions were done by injecting 6-OHDA (50 $\mu \mathrm{g})$ intrathecally with desipramine $(25 \mathrm{mg} / \mathrm{kg})$ given intraperitoneally before the 6-OHDA injection (Sawynok et al., 1991). Mice were then allowed to recover and tested at time points indicated in Results. Brains and spinal cords were then removed to perform histological controls for the lesions.

\section{Behavioral assays and drug administration}

In all behavioral experiments described above, experimenters measuring mechanical withdrawal thresholds or scoring mouse facial expressions were always blinded to the experimental conditions. Mice were randomized to groups from multiple cages to avoid using mice from experimental groups that were cohabitating. Sample size was estimated by performing a power calculation using $G^{\star}$ Power (version 3.1.9.2). With $80 \%$ power, an expectation of $d=2.2$ effect size in behavioral experiments, and $\alpha$ set to 0.05 , the sample size required was calculated as $n=5$ per group. We therefore sought to have an $n=6$ in all behavioral experiments. SD (set at 0.3 ) for the power calculation was based on previously published mechanical threshold data (Moy et al., 2017). All drugs used in this study are shown in Table 1.

von Frey testing. Mice were placed individually in transparent acrylic boxes with wire mesh floors and habituated for $1 \mathrm{~h}$ before testing. von Frey monofilaments (Stoelting) were firmly applied to the plantar surface of each hindpaw for $0.5 \mathrm{~s}$. The up-down method of Dixon (Chaplan et al., 1994) was used to estimate the withdrawal in grams. To induce hyperalgesic priming, we injected either $0.1 \mathrm{ng}$ of human recombinant human interleukin 6 (IL-6; R\&D Systems) in $25 \mu$ l sterile $0.1 \mathrm{~m}$ PBS or $1 \%$ carrageenan (w/v, Sigma-Aldrich) in $25 \mu \mathrm{l}$ sterile PBS into the left hindpaw with an intraplantar injection or we administered $0.1 \mathrm{ng}$ human recombinant BDNF (R\&D Systems) in $5 \mu l$ sterile PBS intrathecal. We measured mechanical withdrawal thresholds at $3,24,48$, and $72 \mathrm{~h}$ after injection. After complete resolution of the initial mechanical or thermal hypersensitivity, mice were assessed for their mechanical withdrawal threshold and subsequently injected in the left hindpaw with $100 \mathrm{ng}$ of prostaglandin $\mathrm{E}_{2}\left(\mathrm{PGE}_{2}\right)$ in $25 \mu \mathrm{l}$ of sterile $\mathrm{PBS}$. Then, mechanical withdrawal thresholds were measured at 3 and $24 \mathrm{~h}$. For all intrathecal injections, drugs were administered in 5 or $10 \mu \mathrm{l}$ sterile PBS to animals anesthetized with isoflurane for no longer than $3 \mathrm{~min}$.

Tail immersion test. Mice were handled and habituated to freely enter into a Plexiglas restrainer. This preliminary step minimizes the effect of stress-induced analgesia. Each mouse was gently handled for $10 \mathrm{~min}$ every day. On test day, $5 \mathrm{~mm}$ of the mouse tail was gently introduced into a water bath preheated at $48^{\circ} \mathrm{C}$. As soon as the mouse withdrew its tail from the hot water, a chronometer was stopped and the latency time was 
recorded. In the absence of an obvious nociceptive reaction, a cutoff of $15 \mathrm{~s}$ was set to prevent tissue damage.

Radiant heat paw-withdrawal, Hargreaves test. Mice were placed on a glass floor, and a focused beam of high-intensity light was aimed at the plantar surface of the hindpaw. The intensity of the light was set to $25 \%$ or $30 \%$ of maximum (IITC Model 390) with a cutoff value of $20 \mathrm{~s}$. The latency to withdraw the hindpaw was measured to the nearest $0.1 \mathrm{~s}$. Tests consisted of three consecutive measures of the paw withdrawal latency, each trial being separated by at least $15 \mathrm{~min}$. The withdrawal latency was calculated as a mean of three independent measures for each animal.

Formalin test. Mice were placed into acrylic boxes with wire mesh floors and habituated for at least $30 \mathrm{~min}$. Following habituation, all mice were given intraplantar injections of formalin $(20 \mu \mathrm{l}, 1 \%$ formalin in saline) into the left hindpaw and placed back into the cylinders. Two genotype blinded investigators recorded the flinching and licking behavior for $1 \mathrm{~min}$ every $5 \mathrm{~min}$ for $1 \mathrm{~h}$. The number of flinches and the licking time were recorded every $5 \mathrm{~min}$ for a period of $1 \mathrm{~min}$ over $60 \mathrm{~min}$. Data are expressed as the number of flinches $(n)$, the licking time (in seconds), as well as the sum of the behaviors. The early phase of the formalin test was defined as $0-10 \mathrm{~min}$, and the late phase as $10-60 \mathrm{~min}$ after injection.

Mouse Grimace Scale. The Mouse Grimace Scale (MGS) was used to quantify affective aspects of pain in mice (Langford et al., 2010). We scored the changes in the facial expressions (using the facial action coding system) 3 and $24 \mathrm{~h}$ after intraplantar injection of test compounds.

Carrageenan-induced inflammation. Paw edema was measured using a caliper before and 3 and $24 \mathrm{~h}$ after injection of $1 \%$ carrageenan into the hindpaw. Mechanical withdrawal threshold was measured afterward at 3 , 24,48 , and $72 \mathrm{~h}$ after injection.

Spared nerve injury-induced neuropathic pain. Neuropathic pain was induced in mice using the spared nerve injury (SNI) surgery model. This surgery consists of exposing and cutting the common peroneal and tibial branches of the sciatic nerve leaving the sural nerve intact (Decosterd and Woolf, 2000). One or 2 weeks after surgery, mechanical sensitivity testing was repeated to ensure that mechanical hypersensitivity had been produced. Following this test, groups of SNI mice were treated with test compounds or lesions at time points indicated in Results.

Rota Rod test. To assess motor coordination, we used the accelerating Rota Rod. Performance on the Rota Rod (AccuScan Instruments), accelerating from 4 to $40 \mathrm{rpm}$ in $300 \mathrm{~s}$, was evaluated for 5 trials per session on 3 consecutive days. A resting time of $180 \mathrm{~s}$ was allowed between each trial. The end of a trial was considered when mice fell off the rod or when they reached $300 \mathrm{~s}$. Latency to fall was recorded for each trial.

Forward-Looking Infrared (FLIR) systems. All procedures were conducted in a temperature-controlled room (ambient temperature of $23 \pm$ $2^{\circ} \mathrm{C}$ ). Animals were allowed to equilibrate in the room for $1 \mathrm{~h}$ before initiation of the study. Color thermograms of the animal's hindpaws were obtained using a FLIR T-Series Thermal Imaging Camera. The T-Series detector system has a focusable distance of $25 \mathrm{~cm}$ minimum. The imager has a temperature range of $-40^{\circ} \mathrm{C}$ to $650^{\circ} \mathrm{C}$ with a temperature indication resolution/sensitivity of $0.04^{\circ} \mathrm{C}$. For image acquisition, animals were allowed to freely move in transparent acrylic boxes with wire mesh floors. The infrared camera was positioned $\sim 30-50 \mathrm{~cm}$ away from the hindpaws, and a thermal image was obtained. Thermogram analysis was performed using the Windows-based PC application of the FLIR system. The software provides the ability to view individual pictures with both hindpaws. For each picture, a straight line was drawn on the plantar surface of both hindpaws and the mean temperature was recorded. At least 3 images were taken per animal, and the average temperatures were used for further analysis. The raw temperatures were then plotted for ipsilateral and contralateral paw for each individual animal.

\section{Perfusion and tissue collection}

Mice were anesthetized using a mixture of ketamine $(80 \mathrm{mg} / \mathrm{kg})$ and xylazine $(12 \mathrm{mg} / \mathrm{kg}$ ) and transcardially perfused with $30 \mathrm{ml}$ of $0.1 \mathrm{M}$ PBS, $\mathrm{pH}$ 7.4. Following the PBS perfusion, mice were fixed with $50 \mathrm{ml}$ of fresh $4 \%$ PFA. The spinal cord and/or brain were removed and further fixed in the same fixative overnight at $4^{\circ} \mathrm{C}$. Consequently, the tissues were transferred to a $30 \%$ sucrose solution in PBS for $48 \mathrm{~h}$ at $4^{\circ} \mathrm{C}$. After complete cryoprotection, the tissues were embedded in OCT (Sakura Finetek) for
Table 2. Antibodies used in the study

\begin{tabular}{llll}
\hline Antibody & Vendor & Catalog no. & Dilution \\
\hline Anti-TH & Millipore & AB152 & $1: 5000$ \\
Anti DBH & Millipore & AB1585 & $1: 5000$ \\
Anti-c-fos & Calbiochem & PC38 & $1: 500$ \\
Anti-calretinin & Swant & $6 B 3$ & $1: 500$ \\
Anti-somatostatin & Millipore & MAB354 & $1: 500$ \\
Anti-TRPV1 & Neuromics & GP14100 & $1: 400$ \\
Anti-PAX2 & R\&D Systems & AF3364 & $1: 200$ \\
Isolectin B4 & Invitrogen & 121411 & $1: 300$ \\
\hline
\end{tabular}

sectioning on a cryostat. Transverse lumbar spinal cord sections were cut at $20 \mu \mathrm{m}$, whereas brain sections were cut at $40 \mu \mathrm{m}$ and stored at $-80^{\circ} \mathrm{C}$ before immunohistochemical procedures.

\section{Bright-field immunohistochemistry}

For DAB immunohistochemistry experiments, mouse spinal cord, freefloating sections were treated with $3 \%(\mathrm{v} / \mathrm{v})$ hydrogen peroxide $\mathrm{H}_{2} \mathrm{O}_{2}$ in PBS to inactivate endogenous peroxidase activity. Nonspecific antigens were blocked by incubating sections in PBS containing 10\% normal goat serum and $0.3 \%$ Triton $\mathrm{X}-100$ for $2 \mathrm{~h}$ at room temperature. Sections were then incubated overnight at $4^{\circ} \mathrm{C}$ with rabbit anti-c-fos antibody (Santa Cruz Biotechnology, SC-52, 1/1000). After three washes in PBS with $0.3 \%$ Triton X-100, sections were incubated for $2 \mathrm{~h}$ in blocking buffer with biotinylated anti-rabbit IgG secondary antibody (Vector Laboratories, $1 / 500)$. After $3 \times 10$ min washes in PBS with $0.3 \%$ Triton $X-100$, sections were incubated in an avidin-biotin-HRP solution (ABC Vectastain Elite kit; Vector Laboratories) for $1 \mathrm{~h}$ at room temperature. Sections were incubated in TBS, pH 7.5, containing 1 tablet of DAB (SigmaFAST) and 1 tablet of urea hydrogen peroxide. All DAB reactions were stopped by three rinses in Tris- $\mathrm{HCl}(0.125 \mathrm{M}, \mathrm{pH} 7.5)$ followed with two washes in PBS. Sections were mounted onto Superfrost slides (Thermo Fisher Scientific). After dehydration in increasing concentrations of ethanol, slides were immersed in xylene and coverslipped with DPX mounting medium (Electron Microscopy Science, \#13510).

\section{Quantification of c-fos-immunoreactive neurons}

An outline was drawn around the dorsal horn of the spinal cord for each section and the lamina delimited according to Watson et al. (2009). The images were thresholded to eliminate background and converted to binary masks using ImageJ (National Institutes of Health, Bethesda, MD), allowing a subsequent automatic detection of the c-fos-positive cells for which the signal is above threshold. After automatic detection of the c-fos-positive cells throughout the entire dorsal horn, the number of immunoreactive cells was then counted per specific lamina. A total of 24 sections were counted per mouse, and 3 mice were used per group for a total of at least 3000 neurons analyzed per condition.

\section{Immunofluorescence and image acquisition}

Tissue sections were washed three times with PBS and permeabilized and blocked with $0.5 \%$ Triton X-100 in PBS containing 10\% normal goat serum. Following permeabilization and blocking for $1 \mathrm{~h}$ at room temperature, primary antibodies were added for overnight incubation at $4^{\circ} \mathrm{C}$ (for details of antibodies, see Table 2). Slides were then washed with PBS 3 times and then incubated for $1 \mathrm{~h}$ with secondary antibody at room temperature. Slides were washed with PBS 3 times once the secondary incubation was completed and then mounted in ProLong Gold mounting media (P36930, Invitrogen). Tissues from all groups were processed together under identical conditions with the same reagents. Confocal microscopy images were obtained with an Olympus FluoView 1200 single-photon confocal microscope. All images are presented as $z$ projections of $z$ stacks. Images were processed using ImageJ.

\section{Colocalization image analysis}

Image analysis was performed using an ImageJ plug-in called Just Another Colocalization Plugin (JACoP) provided in the review by Bolte and Cordelières (2006). To determine calretinin, somatostatin, TRPV1, and PAX2 immunoreactivity in c-fos-positive cells, Li's intensity correlation analysis was calculated for regions of interest in images collected from 
BDNF-primed mice treated spinally with a D1LR agonist (Li et al., 2004). Intensity correlation analysis computes the sum of (current pixel intensity in channel A - channel A's mean intensity) $\times$ (current pixel intensity in channel B - channel B's mean intensity) for each region of interest. Both A channel over B channel and B channel over A channel intensity correlation are represented.

\section{Chromogenic in situ hybridization and FISH}

Brains and spinal cords from adult 8- to 12 -week-old mice were rapidly removed and flash frozen on dry ice. The tissues were then mounted using OCT mounting medium and kept at $-80^{\circ} \mathrm{C}$ until sectioning. Brain and spinal cord were cryosectioned to $20 \mu \mathrm{m}$ thickness and mounted onto Superfrost slides (Thermo Fisher Scientific) and allowed to dry at $-20^{\circ} \mathrm{C}$ for $30 \mathrm{~min}$. The sections were subsequently immersed in prechilled $10 \%$ neutral buffered formalin for 15 min and dehydrated in increasing concentration of ethanol. After complete drying, each section was carefully circled using a hydrophobic barrier pen (Immedge pen, RNAscope, ACDBio) and treated with hydrogen peroxide (RNAscope $2.5 \mathrm{HD}$ kit) for $10 \mathrm{~min}$ to inactivate endogenous peroxidase activity. After two washes in RNAscope buffer, the sections were then treated with Protease Plus for $10 \mathrm{~min}$ at $40^{\circ} \mathrm{C}$. The D1R (D1R, accession no. NM_010076.3, 20 bp, target region: 444-1358), D5R (D5R, accession no. NM_010076.4, 20 bp, target region: 1120-2210), Slc6a3 probes (DAT, accession no. NM_010020.3, 20 bp, target region: 1486-2525) were added to the section and incubated at $40^{\circ} \mathrm{C}$ for $2 \mathrm{~h}$. Afterward, the sections were washed in the RNAscope wash buffer twice and treated with the amplification reagent 1 (AMP1) for $30 \mathrm{~min}$. There were a total of 6 amplification reagents (AMP1-AMP6) with alternating washes of 30 and 15 min incubation period. Finally, Fast RED was added, which in the presence of alkaline phosphatase produces a red precipitate. The sections were then mounted in an aqueous-based media, Prolong Gold (P36930, Invitrogen), and visualized using a single-photon confocal microscope. For each section, the corrected total cell fluorescence (CTCF) was used to quantify the intensity of the signal. To do so, an outline was drawn around the dorsal horn of the spinal cord and different areas of the brains. Using ImageJ, the integrated density, the area, as well as the background noise were measured and the CTCF calculated as equal to the Integrated Density $-($ Area of selected cell $\times$ Mean fluorescence of background readings) (McCloy et al., 2014).

\section{Combined immunofluorescence and in situ hybridization}

After the RNAscope protocol slides were blocked for $1 \mathrm{~h}$ in $10 \%$ normal goat serum, $0.3 \%$ Triton X-100 in $0.1 \mathrm{M} \mathrm{PB}$, DRG slices were incubated IB4-AlexaFluor-488 overnight, and spinal cords were incubated with NeuN antibody (Millipore, MAB377). The next day, the slides were incubated with DAPI (1:5000 in blocking solution) and coverslipped with Prolong Gold and allowed to cure for $24 \mathrm{~h}$ before imaging.

All combined ISH/IHC images were acquired using an FV-3000 confocal microscope (Olympus) and analyzed in CellSens (Olympus). The $40 \times$ confocal $z$-stack images were taken of L4, L5, L6 DRGs from 5 male and 5 female naive C57BL/ 6 mice. For each image, the number of IB4 ${ }^{+}$ neurons was counted using the raw projection image. The total number of neurons displaying visible nuclei were quantified by increasing the background fluorescence (in the 488 channel) using the threshold feature in CellSens (Price and Flores, 2007). We used the percentage of IB4 ${ }^{+}$cells $(\sim 35 \%)$ as a quality-control indicator for our IHC staining as the protease-treatment in the RNAscope ISH protocol can lead to antigen degradation and diminish the quality of the labeling. ISH/IHC colocalization was assessed by counting the number of IB4 ${ }^{+}$and IB4 ${ }^{-}$neurons that showed obvious D1R or D5R mRNA expression within the soma. D1R or D5R mRNA expression outside of the soma (e.g., fibers or nonneuronal cells) was not analyzed. The diameter of the D1R or D5R mRNA-positive neurons was measured by drawing a line across the soma using the ruler tool in CellSens. The number of D1R and D5R mRNApositive cells is shown as the percentage of the total neuronal population.

Data analysis and statistics

All data are represented as mean \pm SEM. All analysis was done using GraphPad Prism 6 version 6.0 for Mac OS X. Single comparisons were performed using Student's $t$ test, and multiple comparisons were per- formed using a two-way ANOVA with Bonferroni post hoc tests for across/within group comparisons. The a priori level of significance was set at $95 \% . F$ and $p$ values and adjusted $p$ values for all experiments can be found in Tables 3-5. The $N$ for each individual experiment is described in the figure legends.

\section{Results \\ Dopaminergic neurons are required for BDNF-induced hyperalgesic priming}

We have previously shown that BDNF injection into the spinal cord of mice (Asiedu et al., 2011; Melemedjian et al., 2013) or the nucleus caudalis of rats (Burgos-Vega et al., 2016) induces hyperalgesic priming. In this model, we inject intrathecal BDNF followed by $\mathrm{PGE}_{2}$ injection into the hindpaw $7 \mathrm{~d}$ later when the animals have completely recovered from the initial hypersensitivity. In primed mice, the $\mathrm{PGE}_{2}$ injection causes mechanical hypersensitivity that lasts for at least $48 \mathrm{~h}$, whereas the injection promotes only a transient $(<1 \mathrm{~h})$ mechanical hypersensitivity in mice previously treated with vehicle (Asiedu et al., 2011). It has been previously shown that lesion of descending DA neurons that originate in A11 blocked the maintenance of priming after IL-6 and carrageenan administration into the hindpaw (J. Y. Kim et al., 2015), but the role of DA neurons in BDNF priming has not been established. To determine whether these neurons play a role in BDNF-induced hyperalgesic priming, we ablated DA neurons by injecting 6-OHDA (50 $\mu \mathrm{g})$ intrathecal with systemic injection of desipramine ( $25 \mathrm{mg} / \mathrm{kg}$ ) $7 \mathrm{~d}$ after BDNF injection (Fig. 1A) to create a selective DA lesion (Sawynok et al., 1991). Intrathecal injection of 6-OHDA after BDNF was sufficient to inhibit subsequent priming revealed after $\mathrm{PGE}_{2}$ treatment in males at $3 \mathrm{~h}$ $(p<0.05$, vehicle vs 6-OHDA $)$ and $24 \mathrm{~h}(p<0.05$, vehicle vs 6-OHDA) (Fig. 1B). Moreover, we have previously shown that ablation of spinal dopaminergic neurons could block the development of an affective pain state measured by the MGS (J. Y. Kim et al., 2015). In mice previously treated with BDNF, we observed a significant increase in the MGS score at $3 \mathrm{~h}$ following $\mathrm{PGE}_{2}$, whereas a similar effect was not observed in mice treated with $6-$ OHDA $(p<0.05$, vehicle vs 6-OHDA) (Fig. 1C). We also tested whether the BDNF-induced priming effect was altered by the 6-OHDA lesion in female mice. The effect of $\mathrm{PGE}_{2}$ was strongly attenuated in female mice with the 6-OHDA lesion at $24 \mathrm{~h}(p<$ 0.05 , vehicle vs 6-OHDA) (Fig. 1D). As we have previously shown, intrathecal injection of $0.1 \mathrm{ng}$ of human recombinant BDNF produced mechanical hypersensitivity that lasts for at least $48 \mathrm{~h}(3,24$, and $48 \mathrm{~h}: p<0.001$, vehicle vs BDNF) (Fig. 1E).

Our previous work indicates that stimulation of spinal D1LRs in mice previously exposed to inflammatory mediators is sufficient to reveal a primed state (J. Y. Kim et al., 2015). We observed that a spinal injection of the D1LR agonist SKF82958 precipitated mechanical hypersensitivity in male mice lasting for $24 \mathrm{~h}$ in BDNF-primed animals, whereas naive animals were completely unaffected ( $3 \mathrm{~h}: p<0.05$, vehicle vs BDNF; $24 \mathrm{~h}: p<0.05$, vehicle vs BDNF) (Fig. $1 F$ ). We observed a similar effect in female mice where SKF82958 produced a robust mechanical hyperalgesia at $3 \mathrm{~h}(p<0.05$, vehicle vs BDNF), but the effect did not persist to $24 \mathrm{~h}$ in female mice ( $p=0.16$, vehicle vs BDNF) (Fig. $1 F$ ). Similarly, intrathecal injection of SCH23390 (3.3 $\mu \mathrm{g})$, a D1LR antagonist, was able to block $\mathrm{PGE}_{2}$-induced hyperalgesia in BDNF-primed male mice at $3 \mathrm{~h}(p<0.05$, vehicle vs SCH23390) (Fig. 1G). Likewise, intrathecal injection of SCH23390 at a dose of $3.3 \mu \mathrm{g}(1 \mathrm{~h}: p<0.05,3 \mathrm{~h}: p<0.05$, vehicle vs SCH23390) or $5 \mu \mathrm{g}$ ( 1 h: $p<0.05,3$ h: $p<0.05$, vehicle vs SCH23390) transiently attenuated neuropathic allodynia compared with vehicle-treated 
Table 3. Two-way ANOVA

\begin{tabular}{|c|c|c|c|c|c|c|c|c|c|c|}
\hline \multirow[b]{2}{*}{ Figure } & \multirow[b]{2}{*}{ Panel } & \multicolumn{3}{|c|}{ Source of variation genotype/treatment } & \multicolumn{3}{|l|}{ Time } & \multicolumn{3}{|c|}{ Interaction } \\
\hline & & dfn, dfd & $F$ & $p$ & dfn, dfd & $F$ & $p$ & $\mathrm{dfn}, \mathrm{dfd}$ & $F$ & $p$ \\
\hline \multirow[t]{5}{*}{1} & B & 1,24 & 15.8 & 0.0007 & 2,24 & 11.92 & 0.0003 & 2,24 & 2.86 & 0.076 \\
\hline & C & 1,24 & 10.74 & 0.0032 & 2,24 & 9.75 & 0.0008 & 2,24 & 2.7611 & 0.083 \\
\hline & $E$ & 1,32 & 81.59 & $<0.0001$ & 3,32 & 7.40 & 0.0007 & 3,32 & 12.88 & $<0.0001$ \\
\hline & $F$ & 1,24 & 6.245 & 0.0197 & 2,24 & 1.74 & 0.1959 & 2,24 & 3.578 & 0.0436 \\
\hline & G & 1,33 & 10.26 & 0.0030 & 2,33 & 22.72 & $<0.0001$ & 2,33 & 3.11 & 0.057 \\
\hline \multirow{3}{*}{3} & $B$ & 1,121 & 11.4 & 0.0010 & 10,121 & 19.78 & $<0.0001$ & 10,121 & 1.76 & 0.074 \\
\hline & $E$ & 1,110 & 9.58 & 0.025 & 10,110 & 19.78 & $<0.0001$ & 10,110 & 0.61 & 0.796 \\
\hline & $F$ & 1,110 & 0.154 & 0.695 & 10,110 & 12.41 & $<0.0001$ & 10,110 & 0.39 & 0.968 \\
\hline \multirow[t]{2}{*}{4} & $E$ & 1,90 & 6.062 & 0.0157 & 14,90 & 1.802 & 0.0501 & 14,90 & 0.6994 & 0.769 \\
\hline & $F$ & 1,165 & 6.821 & 0.0098 & 14,165 & 3.352 & $<0.0001$ & 14,165 & 0.7004 & 0.771 \\
\hline \multirow[t]{8}{*}{5} & $A$ & 1,56 & 3.96 & 0.0512 & 3,56 & 101 & $<0.0001$ & 3,56 & 0.789 & 0.501 \\
\hline & G & 1,80 & 1.981 & 0.1631 & 4,80 & 69.37 & $<0.0001$ & 4,80 & 0.911 & 0.461 \\
\hline & $H$ & 1,27 & 5.387 & 0.0279 & 2,27 & 80.82 & $<0.0001$ & 2,27 & 6.33 & 0.005 \\
\hline & I & 1,70 & 24.16 & $<0.001$ & 6,70 & 25.62 & $<0.0001$ & 6,70 & 0.83 & 0.543 \\
\hline & $J$ & 1,24 & 3.28 & 0.0823 & 2.24 & 23.72 & $<0.0001$ & 2,24 & 0.66 & 0.522 \\
\hline & K & 1,70 & 1.28 & 0.2612 & 6,70 & 25.14 & $<0.0001$ & 6,70 & 1.877 & 0.097 \\
\hline & $L$ & 1,24 & 9.749 & 0.0046 & 2,24 & 17.68 & $<0.0001$ & 2,24 & 1.58 & 0.226 \\
\hline & 0 & 1,55 & 0.031 & 0.8590 & 1,55 & 0.002 & 0.9642 & 1,55 & 1.28 & 0.262 \\
\hline \multirow[t]{5}{*}{6} & $A$ & 1,45 & 28.74 & $<0.001$ & 1,45 & 8.542 & $<0.0001$ & 4,45 & 2.202 & 0.083 \\
\hline & B & 1,27 & 12.66 & 0.0014 & 2,27 & 6.831 & 0.0040 & 2,27 & 2.336 & 0.110 \\
\hline & $C$ & 1,50 & 4.305 & 0.0532 & 2,50 & 40.18 & $<0.0001$ & 2,50 & 0.97 & 0.42 \\
\hline & $D$ & 1,27 & 0.147 & 0.7044 & 2,27 & 32.34 & $<0.0001$ & 2,27 & 0.314 & 0.732 \\
\hline & $E$ & 1,40 & 4.15 & 0.0276 & 3,40 & 4.445 & 0.0087 & 3,40 & 2.282 & 0.045 \\
\hline
\end{tabular}

animals (Fig. 1H). These findings further substantiate a role for D1LRs in hyperalgesic priming in male and female mice and implicate this system in neuropathic pain in the SNI model. We confirmed a reduction of TH-immunoreactive A11 neurons $7 \mathrm{~d}$ after the spinally applied DA toxin, whereas no loss of noradrenergic neurons was observed in the locus ceruleus indicating a selective depletion of DA neurons (Fig. 1I).

We then sought to assess the localization of dopamine transporter (DAT) mRNA expression and the effect of intrathecal 6-OHDA lesions on this DAT mRNA expression. We observed strong DAT mRNA staining in the substantia nigra as a positive control (Fig. $2 A$ ) and a reduction of DAT mRNA in the spinal cord of 6-OHDA-treated mice (Fig. 2B). Interestingly, DAT mRNA was expressed in the superficial dorsal horn where it colocalized specifically with a neuronal marker NeuN (Fig. 2C). Also, we observed, in parasagittal sections of the spinal cord, a very similar pattern of expression between DAT ${ }^{\text {IREScre }} /$ ROSALSL-tdTomato and DAT mRNA. In both cases, these neurons are found at the edge of the dorsal horn, suggesting the existence of cell bodies in outer lamina with axons that run on the rostrocaudal axis as seen with tomato labeling (Fig. 2D). Finally, as previously described (Koblinger et al., 2014), A11 DA neurons show little signs of DAT mRNA but are highly immunoreactive for $\mathrm{TH}$ (Fig. 2E). Therefore, intrathecal injection of 6-OHDA eliminates
A11 DA neurons (J. Y. Kim et al., 2015), although we do not observe signs of DAT mRNA expression in these neurons or their cell bodies in the adult mouse. We also observe a population of DAT-positive neurons in the dorsal horn that are eliminated by the intrathecal 6-OHDA lesion.

\section{DRD5KO mice exhibit thermal hypoalgesia as well as an attenuation of formalin-induced nocifensive behavior in a sex-dependent manner}

We next sought to clarify whether D1 or D5 receptors contribute to hyperalgesic priming. D5Rs are strongly expressed in the dorsal horn of the spinal cord, suggesting that they may play a key role in pain, but this question cannot be addressed with pharmacological tools and mouse genetic tools have not yet been used to address this question. Previous findings have demonstrated that spinal DA receptors can modulate nocifensive behavior in a sexdependent manner (Liu et al., 2017), but the receptors involved in this are also unknown. We therefore sought to thoroughly phenotype DRD5KO mice in a battery of pain tests.

To test whether male and female DRD5KO mice might respond differently to an acute inflammatory insult, we injected $1 \%$ formalin into the hindpaw and recorded the number of flinches and licking behavior over $1 \mathrm{~h}$ in males (Fig. $3 A-D$ ) and females (Fig. $3 E-H$ ). We observed no differences in Phase I of the formalin 
Table 4. Bonferroni post hoc comparison for two-way ANOVA

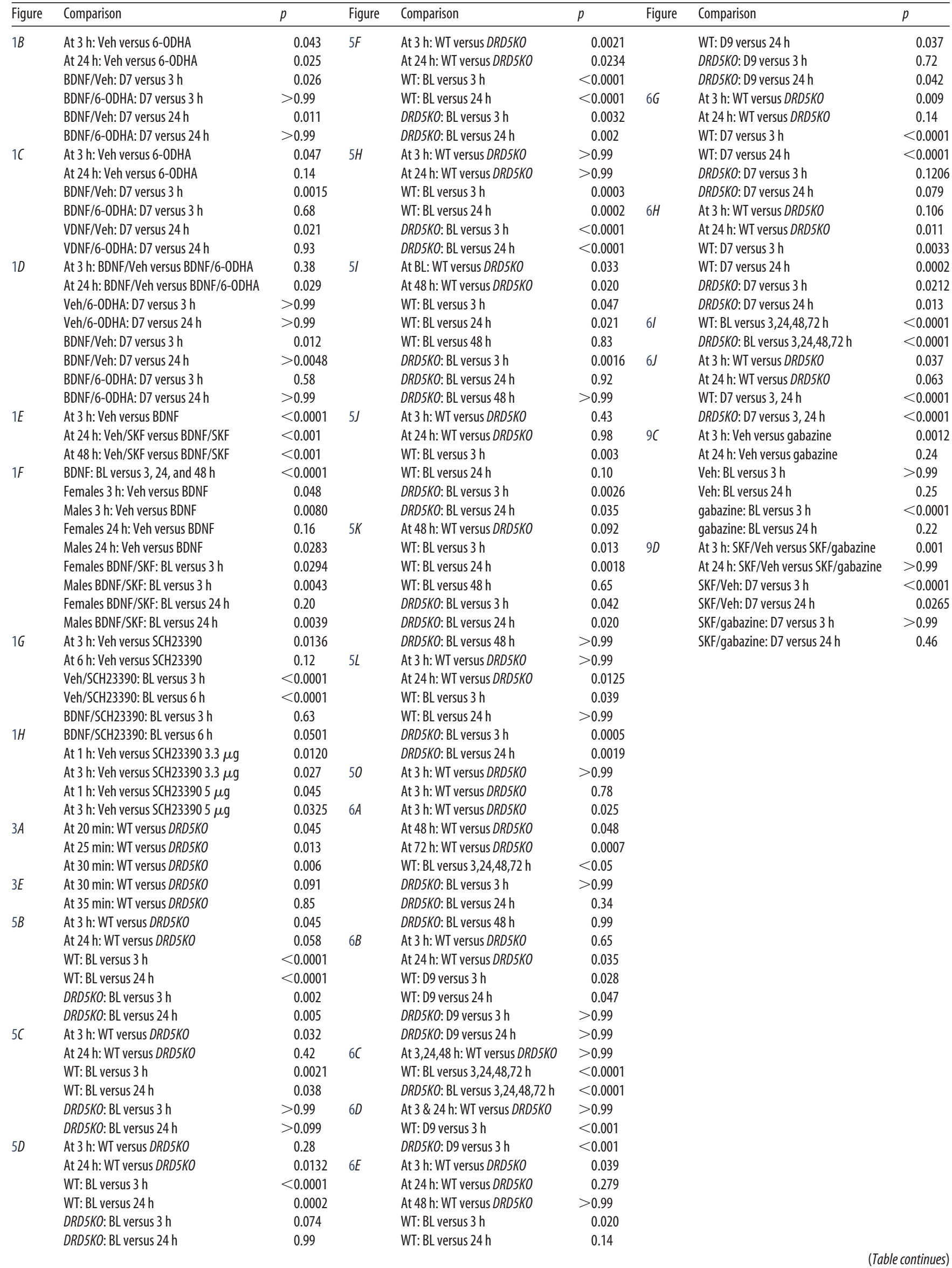


Table 4. Continued

\begin{tabular}{|c|c|c|c|c|c|c|c|c|}
\hline Figure & Comparison & $p$ & Figure & Comparison & $p$ & Figure & Comparison & $p$ \\
\hline \multirow[t]{7}{*}{$5 E$} & At $3 \mathrm{~h}:$ WT versus DRD5KO & 0.4 & & WT: BL versus $48 \mathrm{~h}$ & & & & \\
\hline & At $24 \mathrm{~h}:$ WT versus DRD5KO & 0.0093 & & DRD5KO: BL versus $3 \mathrm{~h}$ & 0.96 & & & \\
\hline & At $48 \mathrm{~h}$ : WT versus DRD5KO & 0.032 & & DRD5KO: BL versus $24 \mathrm{~h}$ & 0.96 & & & \\
\hline & WT: BL versus 3, 24, $48 \mathrm{~h}$ & $<0.0001$ & & DRD5KO: $\mathrm{BL}$ versus $48 \mathrm{~h}$ & 0.989 & & & \\
\hline & DRD5KO: BL versus $3 \mathrm{~h}$ & 0.085 & $6 F$ & At $3 \mathrm{~h}:$ WT versus DRD5KO & 0.012 & & & \\
\hline & DRD5KO: BL versus $24 \mathrm{~h}$ & $>0.99$ & & At $24 \mathrm{~h}$ : WT versus DRD5KO & $>0.99$ & & & \\
\hline & DRD5KO: BL versus $48 \mathrm{~h}$ & $>0.99$ & & WT: D9 versus $3 \mathrm{~h}$ & 0.0007 & & & \\
\hline
\end{tabular}

\section{Table 5. Student's $t$ test}

\begin{tabular}{|c|c|c|c|c|c|}
\hline Figure & Panel & Comparison & Student's $t$ test & $t, \mathrm{df}$ & $p$ \\
\hline \multirow[t]{4}{*}{3} & $C$ & WT versus DRD5KO & Unpaired & $0.28,11$ & 0.76 \\
\hline & $D$ & WT versus DRD5KO & Unpaired & $3.01,11$ & 0.018 \\
\hline & $G$ & WT versus DRD5KO & Unpaired & $0.18,10$ & 0.85 \\
\hline & $H$ & WT versus DRD5KO & Unpaired & $1.08,10$ & 0.30 \\
\hline \multirow[t]{4}{*}{4} & $A$ & WT versus DRD5KO & Unpaired & $3.82,13$ & 0.0021 \\
\hline & $B$ & WT versus DRD5KO & Unpaired & $1.13,9$ & 0.14 \\
\hline & $C$ & WT versus DRD5KO & Unpaired & $4.67,13$ & 0.0036 \\
\hline & $D$ & WT versus DRD5KO & Unpaired & $1.7,11$ & 0.11 \\
\hline 5 & $N$ & Right versus Left & Paired & $2.8,14$ & 0.013 \\
\hline \multirow[t]{9}{*}{7} & $B$ & Caudate: DR1R versus D5R & Multiple $t$ test & $31.02,2$ & 0.007 \\
\hline & & DG: DR1R versus D5R & Multiple $t$ test & $24.73,2$ & 0.009 \\
\hline & & CA1: DR1R versus D5R & Multiple $t$ test & $16.33,2$ & 0.018 \\
\hline & & Amygdala: DR1R versus D5R & Multiple $t$ test & $11.55,2$ & 0.029 \\
\hline & & Cortex: DR1R versus D5R & Multiple $t$ test & $9.60,2$ & 0.031 \\
\hline & & Thalamus: DR1R versus D5R & Multiple $t$ test & $7.98,2$ & 0.031 \\
\hline & & HypoT: DR1R versus D5R & Multiple $t$ test & $5.12,2$ & 0.036 \\
\hline & $D$ & D5R: males versus females & Multiple $t$ test & $3.24,6$ & 0.034 \\
\hline & & D1R: males versus females & Multiple $t$ test & $2.32,9$ & 0.045 \\
\hline \multirow[t]{2}{*}{8} & $B$ & D5R: males versus females & Multiple $t$ test & $4.42,7$ & 0.006 \\
\hline & & D1R: males versus females & Multiple $t$ test & $0.22,7$ & 0.82 \\
\hline \multirow[t]{4}{*}{9} & $B$ & Lamina I & Multiple $t$ test & $0.56,4$ & 0.93 \\
\hline & & Lamina Ili/Ilo & Multiple $t$ test & $0.30,4$ & 0.94 \\
\hline & & Lamina III & Multiple $t$ test & $12.07,4$ & 0.001 \\
\hline & & Lamina IV/V & Multiple $t$ test & $0.03,4$ & 0.97 \\
\hline
\end{tabular}

test in males (Fig. 3C) or females (Fig. 3G). Whereas nocifensive behavior was significantly attenuated during the second phase in males (Phase II, $p<0.05$, WT vs DRD5KO) (Fig. 3D), this effect was not observed in females (Phase II, $p=0.30$, WT vs DRD5KO) (Fig. $3 H$ ). We then measured heat sensitivity using the Hargreaves and tail flick tests to assess whether lack of D5R expression could affect thermal sensitivity. The Hargreaves test revealed a clear increase in the paw-withdrawal latencies in males DRD5KO mice compared with their WT littermates $(p<0.001$, WT vs DRD5KO) (Fig. 4A). Conversely, no differences were observed between female DRD5KOs and their WT control groups $(p=0.14$, WT vs DRD5KO) (Fig. $4 B$ ). In the tail flick test, we observed that male DRD5KOs have longer withdrawal latencies than WT mice ( $p<0.001$, WT vs DRD5KO) (Fig. $4 C$ ). Again, no differences were observed between females DRD5KO compared with their WT littermates ( $p=0.11$, WT vs DRD5KO) (Fig. $4 D$ ). Finally, we tested whether these differences in nociceptive reflexes could be due to motor dysfunction. We found that DRD5KO male ( $p>0.60$, WT vs DRD5KO post hoc analysis at any given time point) (Fig. $4 E$ ) and female ( $p>0.60$, WT vs DRD5KO post hoc analysis at any given time point) (Fig. $4 F$ ) mice showed no differences in the Rota Rod test compared with WT controls.

\section{Sexual dimorphic contribution of D5Rs to carrageenan and IL-6-induced hyperalgesic priming}

We have previously shown that DA, through its action on D1LRs, is a critical factor mediating the central plasticity that controls
IL-6 and carrageenan-induced hyperalgesic priming (J. Y. Kim et al., 2015). We hypothesized that D5Rs may be the crucial receptor subtype for this effect. Because we observed a sexual dimorphism in the formalin test and in thermal sensitivity in DRD5KO mice, we first assessed this hypothesis in male mice. We injected IL-6 $(0.1 \mathrm{ng})$ into the left hindpaw of male DRD5KO mice and recorded mechanical sensitivity in the acute phase as well as following $\mathrm{PGE}_{2}(100 \mathrm{ng})$ treatment. Our results show that IL-6 induces a robust mechanical allodynia in male $D R D 5 K O$ mice as well as in WTs $(p>0.90$, post hoc analysis WT vs DRD5KO for any given time point) (Fig. $5 A$ ). However, $\mathrm{PGE}_{2}$-induced priming is attenuated in DRD5KO mice at $3 \mathrm{~h}(p<0.05$, WT vs DRD5KO) but not at $24 \mathrm{~h}(p=0.058$, WT vs DRD5KO) compared with WT mice (Fig. $5 B$ ). Those findings are in agreement with previous data showing that blocking D1LRs does not affect acute mechanical hypersensitivity in response to IL- 6 but attenuates the response to $\mathrm{PGE}_{2}$ in the priming phase (J. Y. Kim et al., 2015). The lack of D5Rs significantly attenuated the development of an affective pain state in male DRD5KO mice at $3 \mathrm{~h}(p<0.05$, WT vs DRD5KO) after IL-6 as well as $24 \mathrm{~h}$ after $\mathrm{PGE}_{2}(p<0.05$, WT vs DRD5KO) (Fig. 5C,D), corroborating an important role of D5Rs in hyperalgesic priming induced by IL-6 injection.

We then assessed hyperalgesic priming induced by carrageenan, which is a polysaccharide that binds to TLR4, activating $\mathrm{Bcl} 10$ and the $\mathrm{NF} \kappa \mathrm{B}$ pathway (Bhattacharyya et al., 2011). Carrageenan intraplantar injection (1\%) induced a robust mechanical hypersensitivity in WT male mice, whereas this response was blunted in DRD5KO mice at $24 \mathrm{~h}(p<0.01$, WT vs DRD5KO) and $48 \mathrm{~h}(p<0.05$, WT vs DRD5KO) (Fig. $5 E)$. We did not observe a significant change in the mechanical threshold in DRD5KO mice compared with baseline ( $p=0.085$, BL vs $3 \mathrm{~h}$ ) (Fig. $5 E$ ). $\mathrm{PGE}_{2}$ injection in primed mice revealed a significant decrease in priming in male DRD5KO mice at $3 \mathrm{~h}(p<0.01$, WT vs $\mathrm{D} 5 \mathrm{KO})$ and $24 \mathrm{~h}(p<0.05$, WT vs D5KO) after injection compared with WT mice (Fig. $5 F$ ). Consistent with formalin and thermal sensitivity sexual dimorphisms, no differences were observed in response to carrageenan in female DRD5KO mice ( $p=$ 0.16 , WT vs D5KO) (Fig. 5G). Although a significant difference was observed at day 9 after carrageenan between WT and DRD5KO female mice (D9 point in Fig. 5H: $p<0.05$, WT vs $D R D 5 K O)$, the amplitude of the hyperalgesic priming, as measured by subsequent $\mathrm{PGE}_{2}$ injection, was identical in female DRD5KO and WT mice at 3 (WT: BL vs 3 h: $p<0.001$; DRD5KO: BL vs 3 h: $p<0.0001$ ) and 24 h (WT: BL vs 24 h: $p<0.0001$; DRD5KO: BL vs 24 h: $p<0.0001$ ) (Fig. 5H). Then, to test whether thermal sensitivity after carrageenan could also be affected in the DRD5KOs, we measured paw-withdrawal latencies using the Hargreaves test. We observed that carrageenan produced a robust hypersensitivity in WT and DRD5KO male mice $(p<0.05$ WT: BL vs 3 and $24 \mathrm{~h} ; p<0.05$ DRD5KO: BL vs 3 and $24 \mathrm{~h})$. However, male DRD5KO mice exhibited a reduced thermal sensitivity compared with their WT littermates at baseline 
A

\begin{tabular}{|ccc|} 
BDNF i.t & 6-OHDA i.t + Des. & PGE2 i.pl \\
\hline Day 1 & Day 7 & Day 14 \\
\hline
\end{tabular}

B

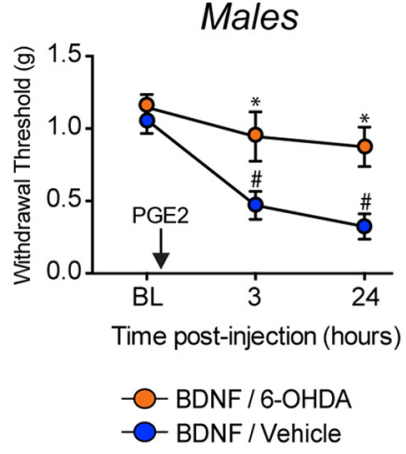

E

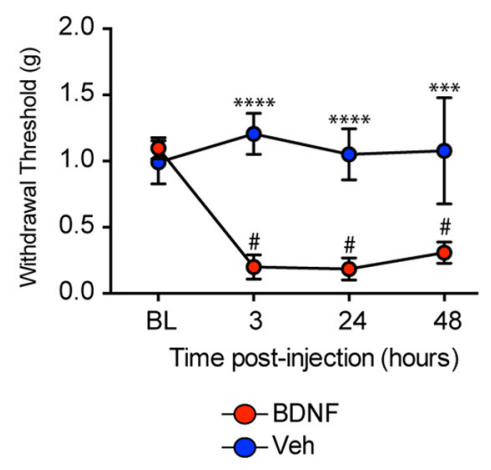

H

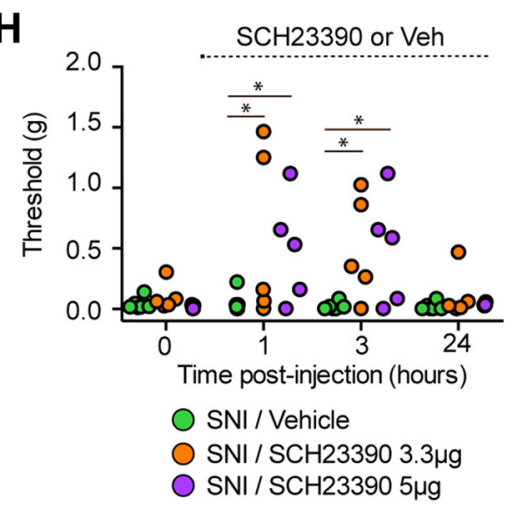

C

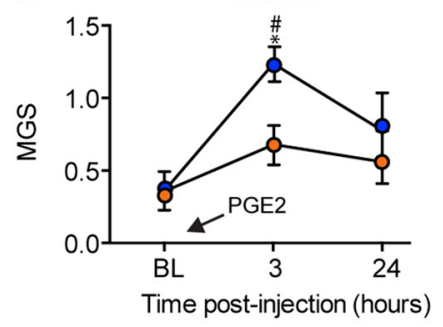

BDNF / 6-OHDA

BDNF/Vehicle

F

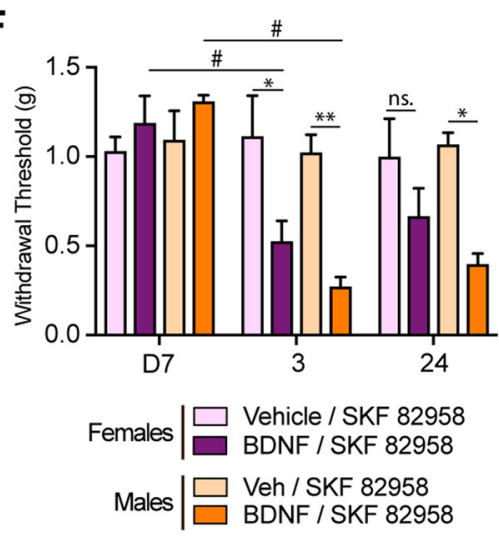

I

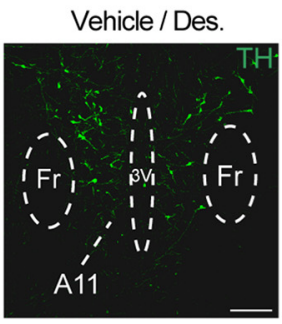

D

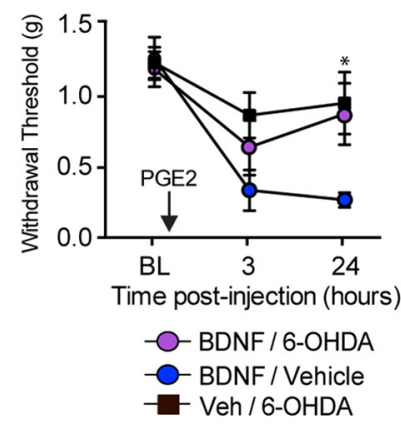

G

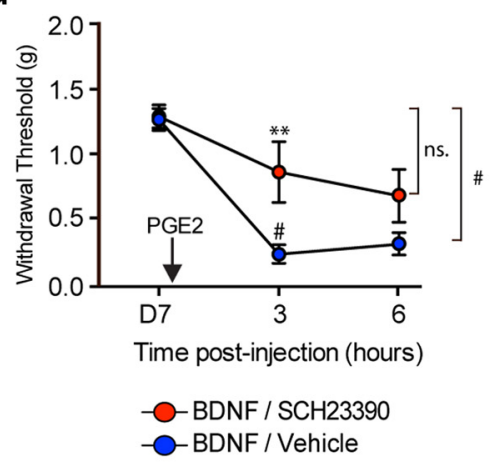

Vehicle/Des.
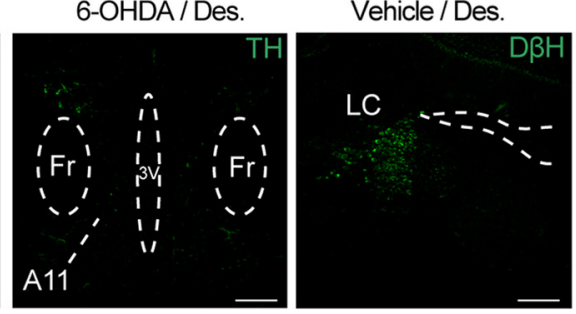

6-OHDA / Des.

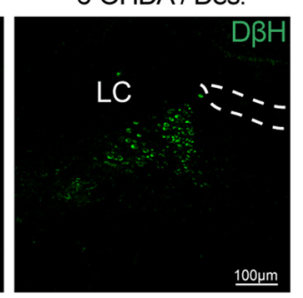

Figure 1. Spinal DA projections control BDNF-induced hyperalgesic priming and contribute to neuropathic pain. $\boldsymbol{A}$, Timeline diagram showing 6-0HDA injection in primed mice. $\boldsymbol{B}$, Subsequent intraplantar injection of $\mathrm{PGE}_{2}$ in mice that were previously treated with BDNF caused mechanical hypersensitivity that lasted for $24 \mathrm{~h}$, whereas DA lesion $7 \mathrm{~d}$ after BDNF injection attenuated hyperalgesic priming. $N=6-8$ mice per group. $C$, DA lesion also attenuated PGE 2 -induced increase in MGS scores in BDNF-primed mice. $N=6-8$ mice per group. $D, D A$ lesion also attenuated $\mathrm{PGE}_{2}$-induced allodynia in females BDNF-primed mice. $N=6$ or 7 mice per group. $\boldsymbol{E}$, Intrathecal injection of BDNF produces mechanical hypersensitivity that lasted for at least $48 \mathrm{~h}$. $N=5$ or 6 mice per group. $\boldsymbol{F}$, At day 7, after complete recovery, spinal injection of the D1/D5 agonist in males and females, SKF82958 only reveals priming in animals previously treated with BDNF. $N=5-7$ mice per group. $\boldsymbol{G}$, Intrathecal injection of the D1/D5 antagonist SCH23390 at the time of PGE 2 blocks mechanical hypersensitivity in BDNF-primed mice. $N=5$ or 6 mice per group. $\boldsymbol{H}$, Intrathecal injection of the D1/D5 antagonist transiently attenuates neuropathic mechanical allodynia at 1 and $3 \mathrm{~h}$ after intrathecal injection. $N=5$ or 6 mice per group. $I$, Intrathecal injection of 6-0HDA reduces $A 11$ hypothalamic DA neurons (6-OHDA + desipramine) without disrupting noradrenergic neurons in the locus ceruleus. Images are representative of $N=3$ mice per group. ${ }^{*} p<0.05$, comparing WT versus DRD5KO (two-way ANOVA with Bonferroni post hoc test). ${ }^{* *} p<0.01$, comparing WT versus DRD5KO (two-way ANOVA with Bonferroni post hoc test). ${ }^{* *} p<0.001$, comparing WT versus DRD5KO (two-way ANOVA with Bonferroni post hoc test). ${ }^{* * * *} p<0.0001$, comparing WT versus DRD5KO (two-way ANOVA with Bonferroni post hoc test). ${ }^{*} p<0.05$, compared with baseline (two-way ANOVA with Bonferroni post hoc test).

$(p<0.05$, WT vs DRD5KO) and again at $48 \mathrm{~h}(p<0.05$, WT vs DRD5KO) after carrageenan (Fig. 5I). We did not observe a clear thermal hyperalgesia in response to $\mathrm{PGE}_{2}$ injection on day 9 after carrageenan injection. In an identical experiment in female $D R D 5 K O$ and the WT mice, we did not see any significant differences at any time points (Fig. $5 K)(p=0.26$, WT vs $D R D 5 K O)$, but thermal hypersensitivity to carrageenan injection was present at 3 and $24 \mathrm{~h}$ after injection in both genotypes.

Because we observed decreased mechanical hypersensitivity and a more rapid resolution of thermal hypersensitivity in DRD5KO male mice, we assessed the degree of carrageenan-induced inflammation in these mice. Edema measurements revealed no gross 
A

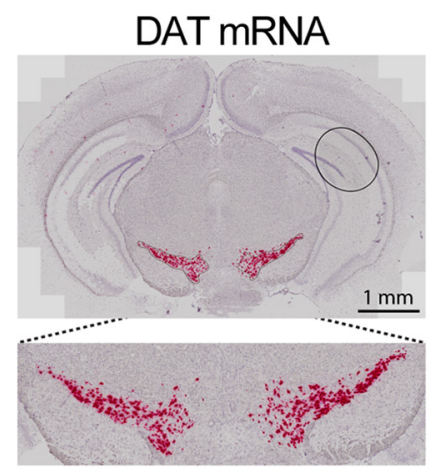

Negative control
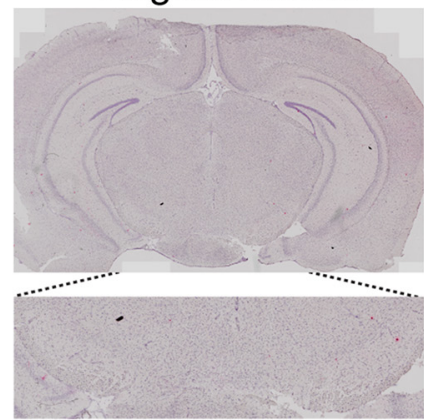

D
B

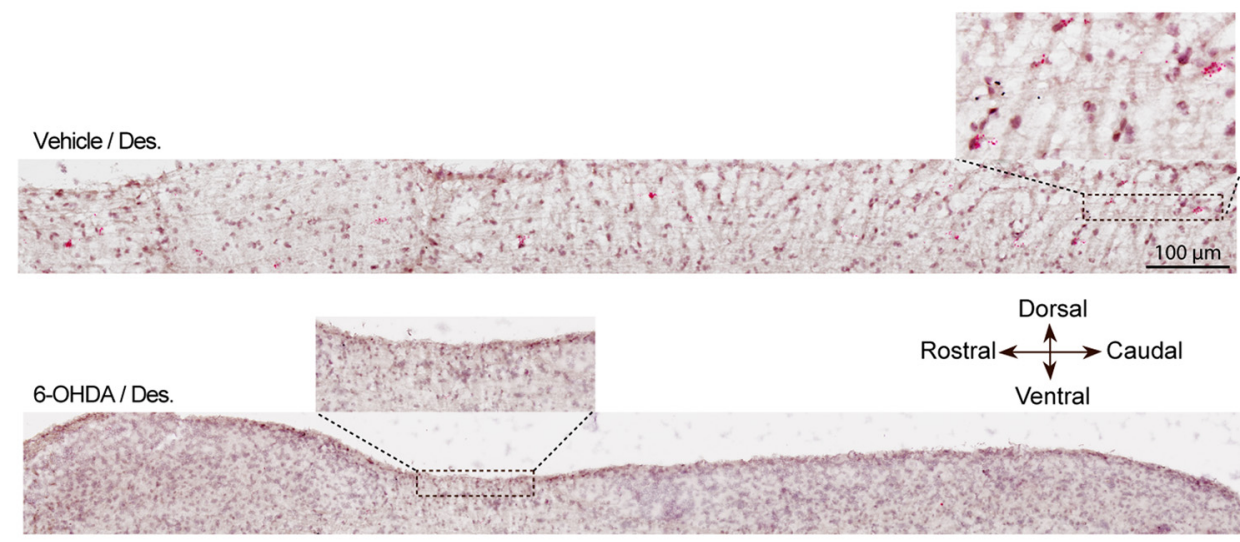

C
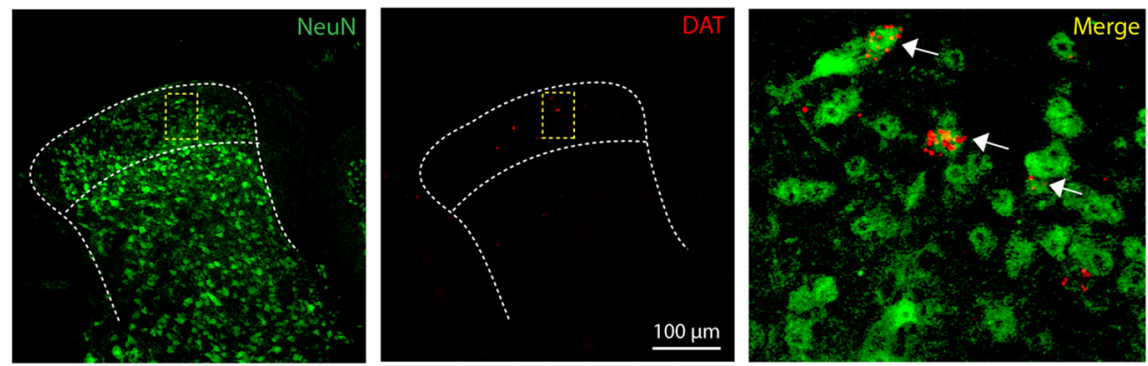

E

\section{DAT mRNA}

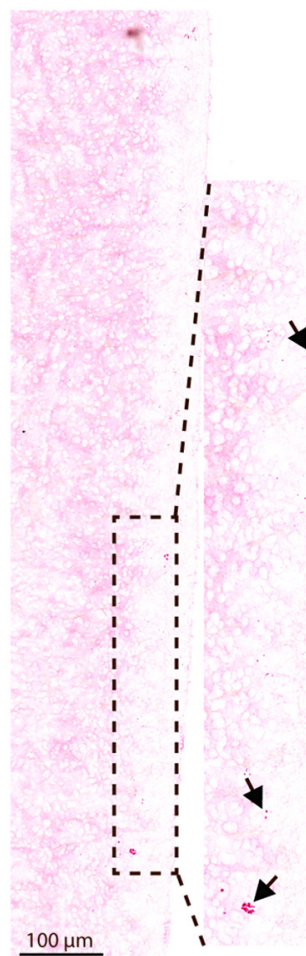

$\mathrm{TH}$
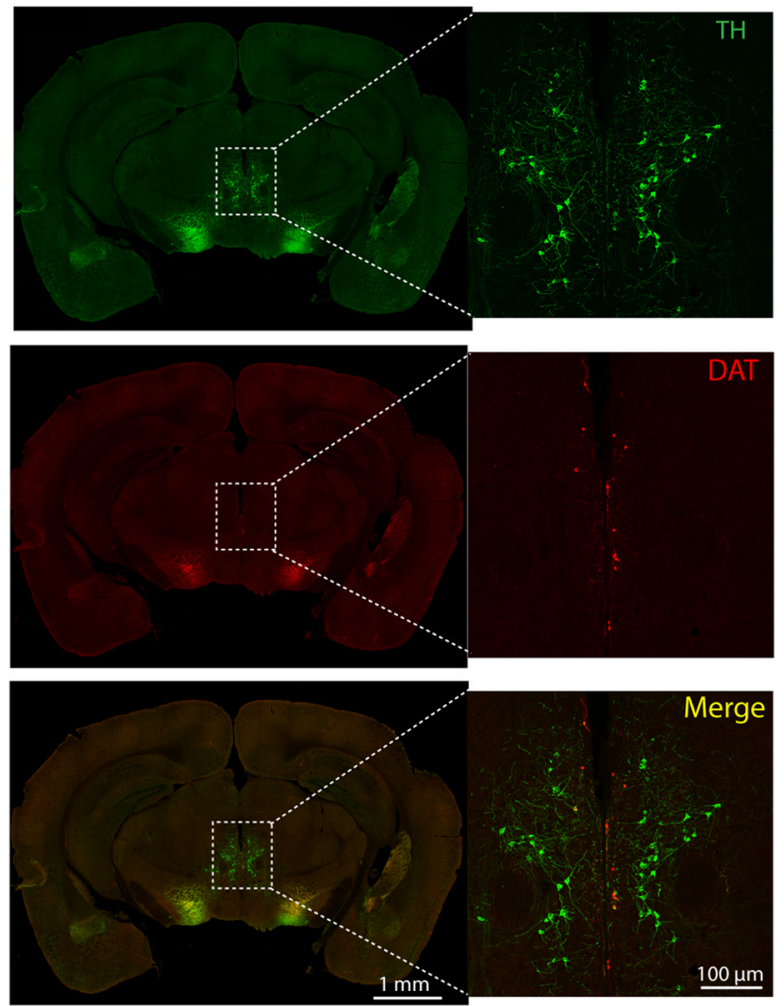

Figure 2. Spinal DA lesion reduces the number of TH-immunoreactive neurons in A11 and spinal cord DAT expression. A, DAT in situ hybridization probe shows a specific signal in the substantia nigra, whereas the negative control probe shows no signal. $\boldsymbol{B}$, Parasagittal sections of the spinal cord show DAT mRNA expression in the dorsal horn. Red punctate are visible throughout the rostrocaudal axis, whereas spinal DA lesion drastically decreases the level of DAT mRNA expression. $N=3$ per group. $C$, Coronal section of the spinal cord showing DAT mRNA expression in the dorsal horn mainly localized in superficial laminae and overlapped with a neuronal marker (NeuN). $N=3$ per group. D, Illustration of the DAT expression pattern in a DAT IREScre/ROSA-LSL-tdTomato animal as well as DAT mRNA expression using RNAscope. $\boldsymbol{E}$, Representative coronal section of the brain showing a high level of TH immunoreactivity in the A11 nucleus, whereas DAT mRNA signal is not readily detected in this region. Mice in these experiments were female and male. 


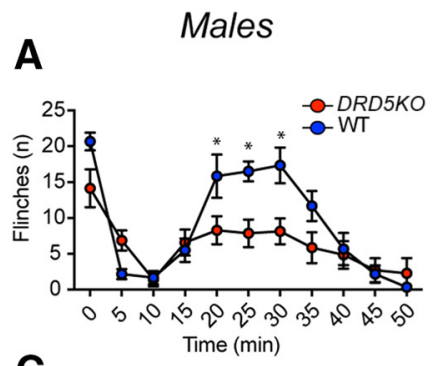

C

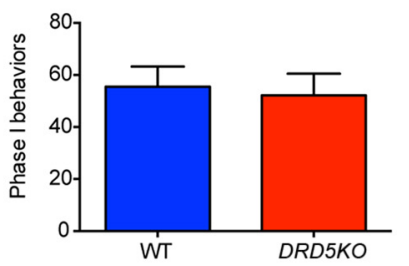

B

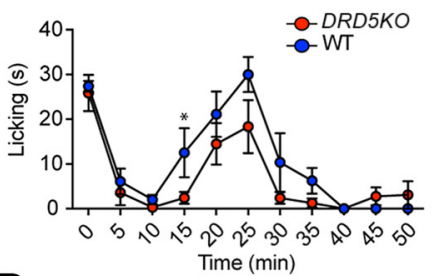

D

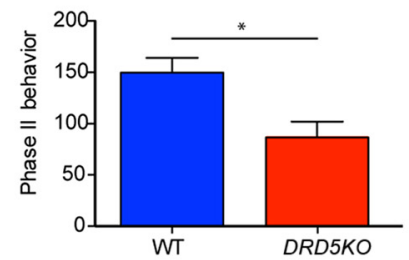

E

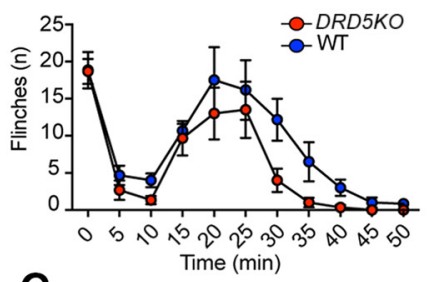

G

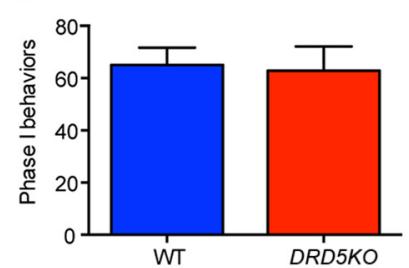

Females

$\mathbf{F}$

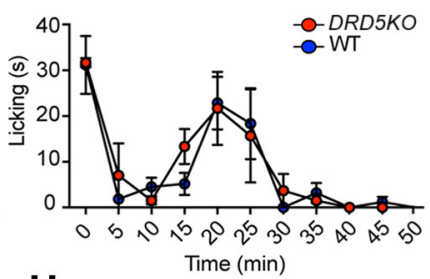

H

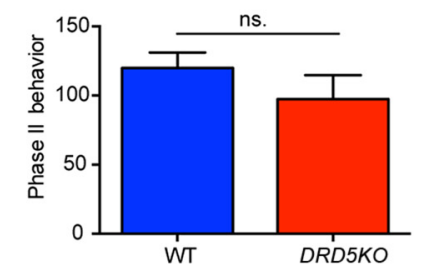

Figure 3. Formalin-induced nocifensive behavior is attenuated in males DRD5KO mice. $A, B$, Formalin-induced flinching and licking behavior is reduced in $D R D 5 K O$ male mice. $\boldsymbol{C}, \boldsymbol{D}$, The second phase of the formalin test is significantly blunted in male DRD5KO compared with their WT littermates. $N=6$ mice per group. $\boldsymbol{E}, \boldsymbol{F}, D R D 5 K O$ does not affect formalin-induced flinching or licking behavior in female mice. $\mathbf{G}, \boldsymbol{H}$, No significant differences were observed in the formalin test phases in female WT and DRD5KO mice. $N=6$ mice per group. ${ }^{*} p<0.05$ (two-way ANOVA with Bonferroni post hoc test).

A

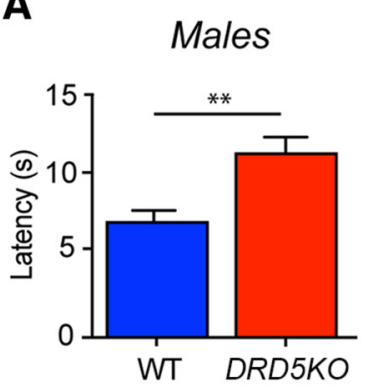

B

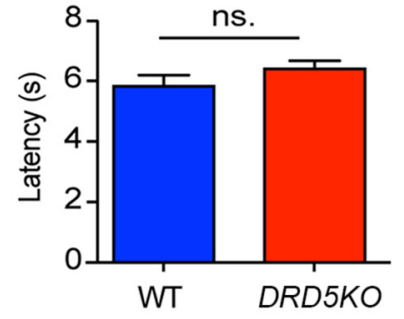

Males

E

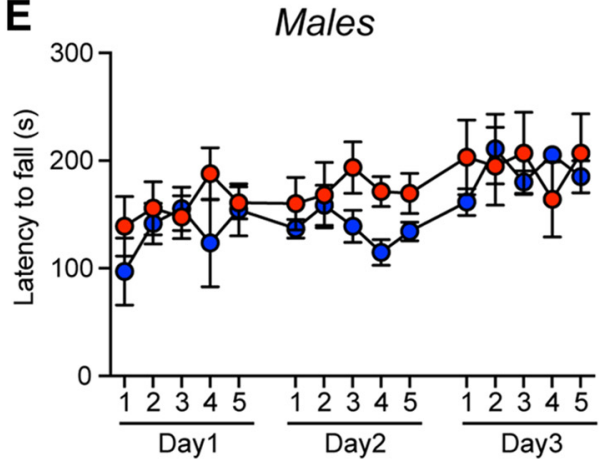

C

Males

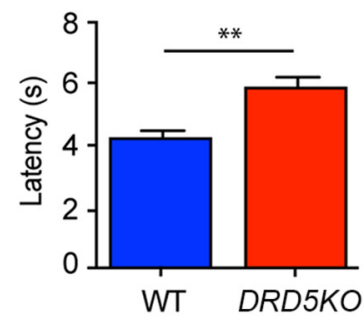

D

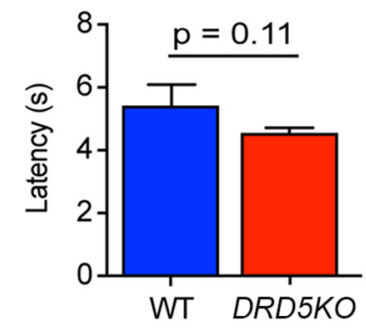

F

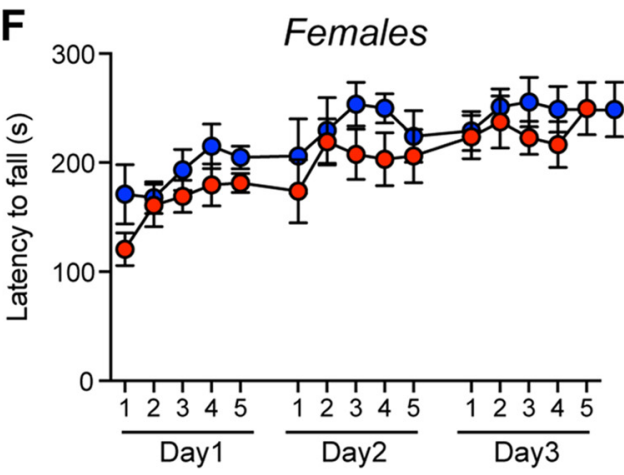

Figure 4. Male DRD5KO mice exhibit thermal hypoalgesia. $\boldsymbol{A}$, Thermal sensitivity is significantly impaired in male DRD5KO compared with WT mice in the Hargreaves test. $N=6-8$ mice per group. $\boldsymbol{B}$, Baseline thermal sensitivity is similar between female DRD5KO and WT mice in the Hargreaves test. $N=5-7$ mice per group. $\boldsymbol{C}$, Male DRD5KO show an increased tail-withdrawal latency compared with WT mice in the tail flick test at $49^{\circ} \mathrm{C} . N=6$ mice per group. $\boldsymbol{D}$, No differences were observed in thermal sensitivity between female $D R D 5 K O$ and WT. $N=6$ mice per group. $\boldsymbol{E}, \boldsymbol{F}$, Motor skill learning and motor coordination are not impaired in male or female DRD5KO mice. $N=6-8$ mice per group. ${ }^{* *} p<0.01$ (two-way ANOVA with Bonferroni post hoc test).

differences between male DRD5KO and WT mice at 3 and $24 \mathrm{~h}$ after carrageenan injection ( $p=0.082$, WT vs $D R D 5 K O$ ) (Fig. $5 J$ ), whereas the size of edema was significantly greater in $D R D 5 K O$ female mice compared with WT at the $24 \mathrm{~h}$ time point after injection $(p<0.05$, WT vs DRD5KO) (Fig. $5 L$ ). Because increased blood flow in inflammation also changes the temperature of the tissue, we tested whether carrageenan-induced increases in paw temperature could be attenuated in the DRD5KO mice. Using a hand-held FLIR thermal camera (Fig. 5M), we found that carrageenan injection significantly increased the average temperature of the ipsilateral paw (paired $t$ test, ipsilateral vs contralateral at $3 \mathrm{~h}: p<0.05)($ Fig. $5 N$ ) as has been previously described (Sanchez et al., 2008). However, no noticeable differences were observed between male WT or $D R D 5 K O$ mice at either 3 or $24 \mathrm{~h}$ after carrageenan injection (at 3 h: $p>0.99$; at 24 h: $p=0.78$ ) (Fig. 5O).

BDNF-induced pain and hyperalgesic priming are regulated by D5Rs in male mice and D1Rs in female mice We then tested whether or not D5Rs play a role in the pain response to BDNF and/or BDNF-induced priming. To do so, we 

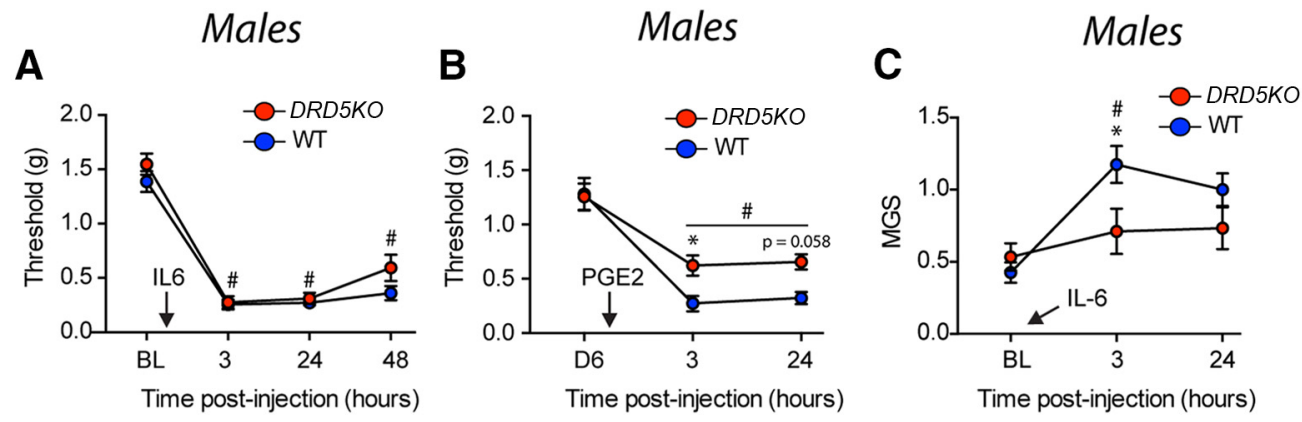

Males

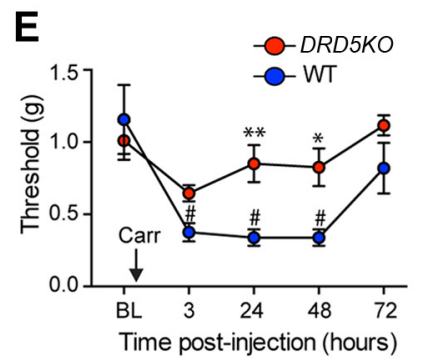

I

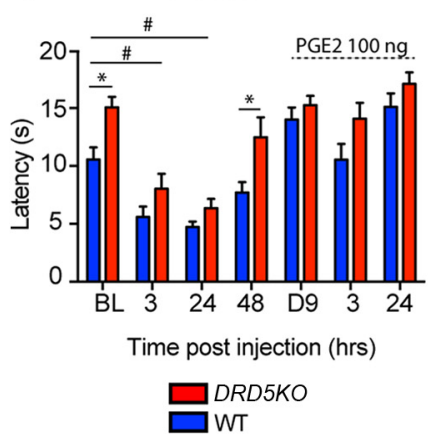

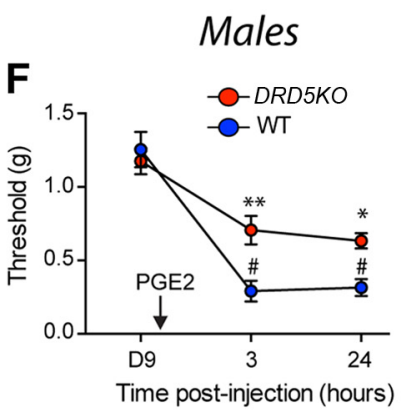

J Males
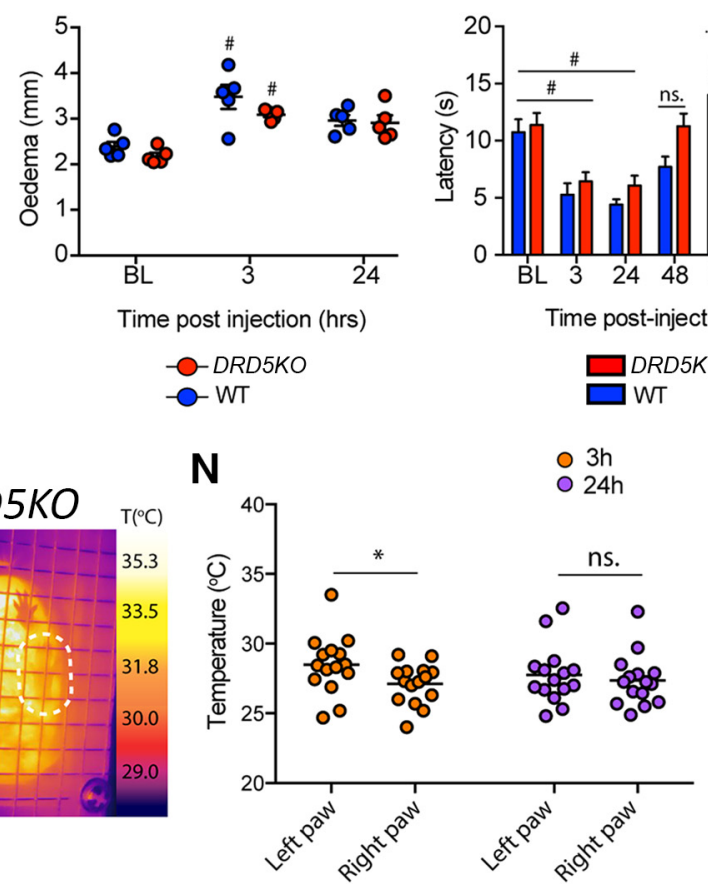

K

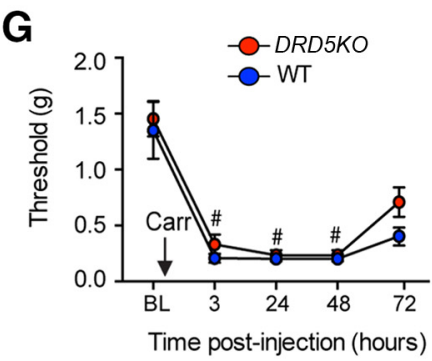

Females

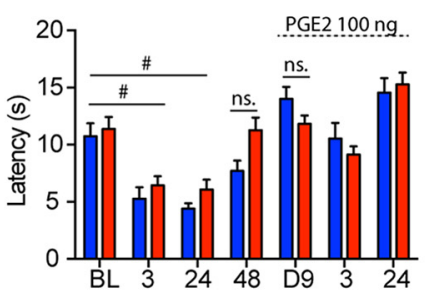

Time post-injection (hours)
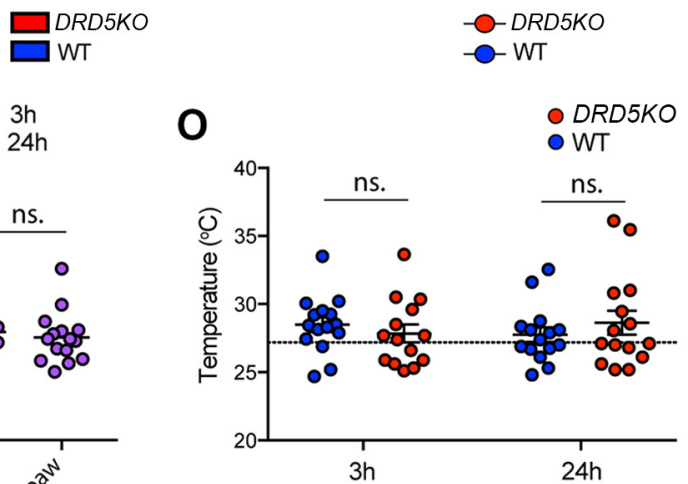

M

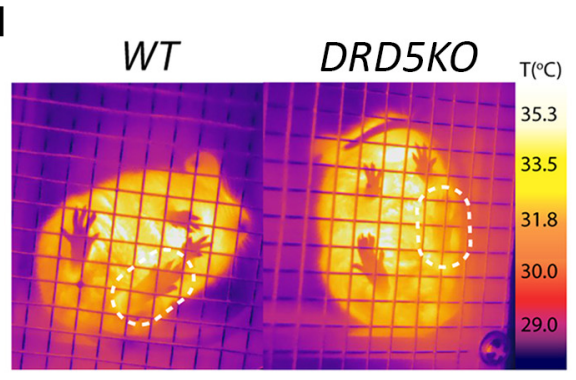

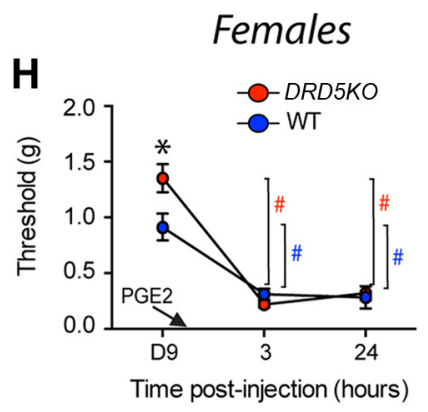

L Females

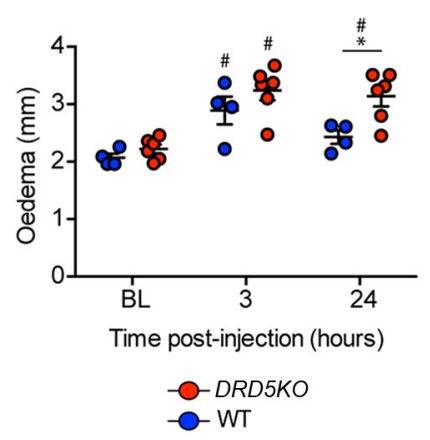

D

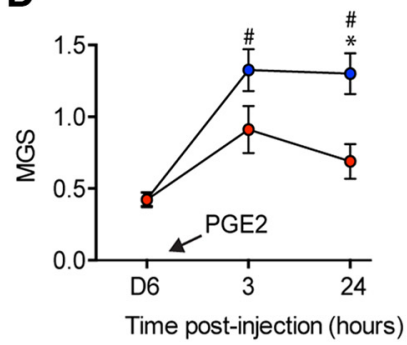

3

Figure 5. Carrageenan- and IL-6-induced hyperalgesic priming is reduced in male, but not female, DRD5KO mice. A, IL-6 injection induces mechanical hypersensitivity in male WT and DRD5KO mice that lasts for at least $48 \mathrm{~h} . N=6$ mice per group. $B$, Subsequent injection of $P_{G} E_{2}$ reveals hyperalgesic priming in male WT mice less in DRD5KO mice. $N=6$ mice per group. C, Similarly, IL-6 failed to induce an increase in the mouse grimace scores in DRD5KO mice at $3 \mathrm{~h} . \mathrm{N}=6$ mice per group. D, Finally, DRD5KO mice exhibit a significant reduction in MGS scores compared with WT mice after injection of $\mathrm{PGE}_{2}$ at 3 and $24 \mathrm{~h} . N=6$ mice per group. $\boldsymbol{E}$, Intrathecal injection of carrageenan (1\%) produces a strong mechanical hypersensitivity in male WT mice that is significantly reduced in DRD5KO mice. $\boldsymbol{F}$, Moreover, $\mathrm{PGE}_{2}$-induced mechanical hypersensitivity is observed in primed DRD5KO mice. $N=6$ mice per group. $\boldsymbol{G}$, Intrathecal injection of carrageenan produces a robust mechanical hypersensitivity in female WT and DRD5KO mice that lasted for $72 \mathrm{~h} . N=5$ or 6 mice per group. $\boldsymbol{H}$, Injection of PGE reveals the presence of priming in both genotypes. $N=6$ mice per group. I, Carrageenan-induced thermal hypersensitivity is significantly attenuated in male DRD5KO mice at $48 \mathrm{~h} . N=5$ or 6 mice per group.J, However, the size of the edema is comparable between WT and DRD5KO mice. $N=6$ mice per group. $K$, Carrageenan-induced thermal hypersensitivity is similar between WT and DRD5KO female mice. $N=6$ mice per group. $L$, Yet, a significant increase in the size of the edema in the female DRD5KO mice was observed $24 \mathrm{~h}$ after treatment. $N=6$ mice per group. $M$, Changes in paw temperature as a measure of inflammation observed in the left paw injected with carrageenan compared with the right paw. $N$, Carrageenan induces a significant increase in temperature of the ipsilateral compared with the contralateral paw at $3 \mathrm{~h}$, but not at $24 \mathrm{~h}$. $N=12-14$ per group. $\mathbf{0}$, No differences were observed in the temperature of the injected paw between WT and DRD5KO mice at 3 and $24 \mathrm{~h}$. ${ }^{*} p<0.05$, comparing WT versus DRD5KO (two-way ANOVA with Bonferroni post hoc test). ${ }^{* *} p<0.01$, comparing WT versus DRD5KO (two-way ANOVA with Bonferroni post hoc test). ${ }^{*} p<0.05$, compared with baseline (two-way ANOVA with Bonferroni post hoc test). 

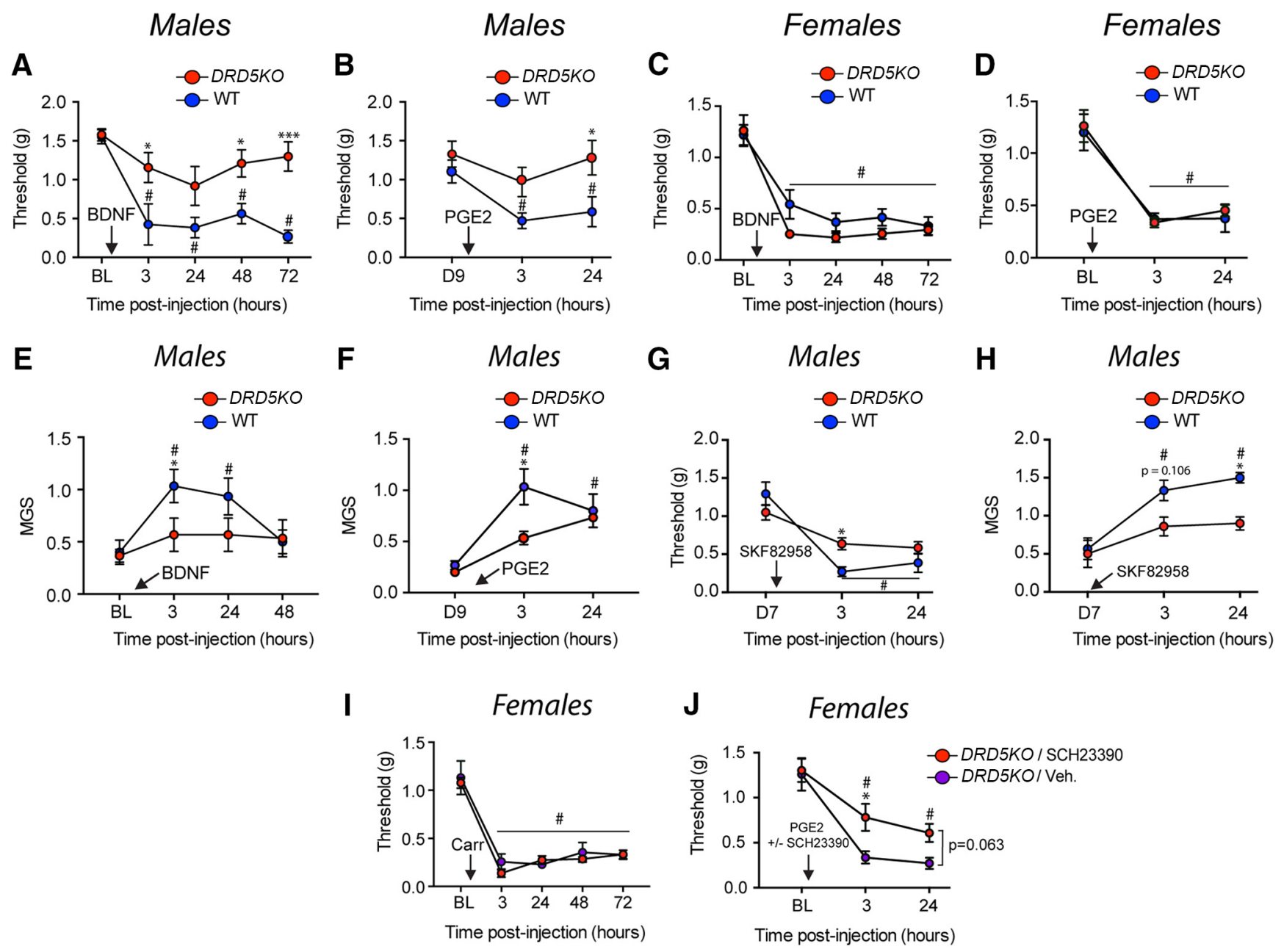

Figure 6. Spinal D5Rs and D1Rs are predominantly involved in the maintenance of hyperalgesic priming in males and females, respectively. $A, B D N F$ fails to produce mechanical hypersensitivity in male DRD5KO mice but produces robust effects in WT mice. $N=6$ mice per group. $B$, Subsequent priming revealed by $P_{G E}$ is blocked in male $D R D 5 K O$ mice at $24 \mathrm{~h} . N=6$ mice per group. $C$, In female mice, BDNF produces a robust mechanical hypersensitivity in WT and DRD5KO mice that lasts for at least $72 \mathrm{~h}$. $D$, Again, injection of PGE 2 reveals priming in female $D R D 5 K O$ and WT mice. $N=$ 5 or 6 mice per group. $E$, In males, the lack of D5 receptors blocks the development of an affective pain state after an intrathecal injection of BDNF. $\boldsymbol{F}_{\text {, PGE }}$-induced grimacing in BDNF-primed mice is attenuated in male DRD5KO mice at $3 \mathrm{~h}$ after injection. $N=6$ mice per group. G, Spinal injection of the D1LR agonist SKF82958 revealed a smaller magnitude of hyperalgesic priming induced by an intraplantar injection of IL-6 in DRD5KO mice, suggesting only a small role for D1Rs in priming in males. $N=6$ mice per group. $H$, Likewise, male DRD5KO mice primed with IL-6 exhibited an attenuation of an affective pain state after spinal injection of the D1RL agonist compared with their WT littermates. $N=5$ or 6 mice per group. I, Intraplantar injection of carrageenan $1 \%$ produces a strong mechanical hypersensitivity in female DRD5KO and WT mice. J, Intraplantar injection of a D1RL antagonist blocks hyperalgesic priming revealed by PGE 2 injection in female DRD5KO mice. $N=6$ mice per group. ${ }^{*} p<0.05$, WT versus DRD5KO (two-way ANOVA with Bonferroni post hoc test). ${ }^{* * *} p<0.001$, WT versus DRD5KO (two-way ANOVA with Bonferroni post hoc test). ${ }^{*} p<0.05$, compared with baseline (two-way ANOVA with Bonferroni post hoc test).

gave intrathecal injections of BDNF and evaluated mechanical sensitivity as well as MGS scores. BDNF induced substantially less mechanical hypersensitivity in male DRD5KOs at $3 \mathrm{~h}(p<0.05$, WT vs D5KO), $48 \mathrm{~h}(p<0.05$, WT vs D5KO), and $72 \mathrm{~h}(p<0.001$, WT vs D5KO) compared with their WT littermates (Fig. 6A). There was also a reduction in the response to $\mathrm{PGE}_{2}$ in BDNF-primed DRD5KO male mice at $24 \mathrm{~h}(p<0.05$, WT vs D5KO) (Fig. 6B). In females, there was no significant difference between DRD5KOs and their WT littermates at any time points ( $p>0.90$, WT vs DRD5KO) (Fig. 6C); and, again, no difference was seen in female mice when priming was assessed with $\mathrm{PGE}_{2}$ injection (Fig. $6 D$ ). In addition to the differences in mechanical hypersensitivity, BDNF-induced grimacing was attenuated at $3 \mathrm{~h}$ in male DRD5KO mice $(p<0.05$, WT vs $D R D 5 K O$ ) (Fig. 6E), and a similar effect was observed after $\mathrm{PGE}_{2}$ injection with a significant attenuation of MGS scores at $3 \mathrm{~h} \mathrm{com-}$ pared with WT mice $(p<0.05$, WT vs DRD5KO) (Fig. $6 F)$. We did not examine MGS scores in females because no differences were observed in mechanical hypersensitivity in response to BDNF in female DRD5KO mice.

Because no selective D1R or D5R agonist is available, we took advantage of the DRD5KO mice to test whether stimulation of D1Rs is sufficient to reveal the presence of priming in mice previously exposed to IL-6, which produces equal acute mechanical sensitivity in WT and DRD5KO mice. When we spinally injected SKF82958, a D1LR agonist, in male DRD5KO and WT mice that had been previously treated with IL-6, we observed a significant reduction of D1LR-induced mechanical sensitivity at $3 \mathrm{~h}(p<$ 0.05 , WT vs D5KO) but not $24 \mathrm{~h}$ ( $p=0.14$, WT vs D5KO) (Fig. $6 G)$. D1LR agonist-induced affective pain behavior was significantly blunted in male DRD5KO mice at $24 \mathrm{~h}(p<0.05$, WT vs D5KO) (Fig. 6H). These findings strongly suggest a preferential role of D5Rs over D1Rs in neuroplasticity mechanisms underlying hyperalgesic priming in male mice. However, our present findings clearly demonstrate a sexual dimorphic role of spinal DA 
A

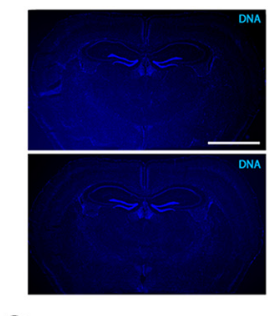

C
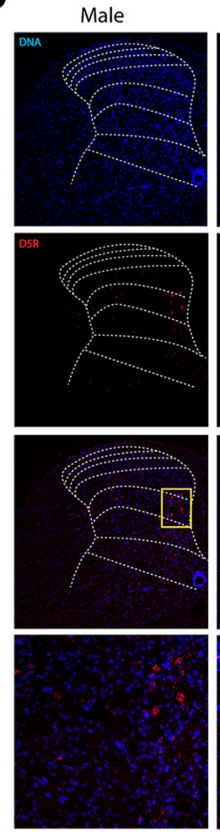
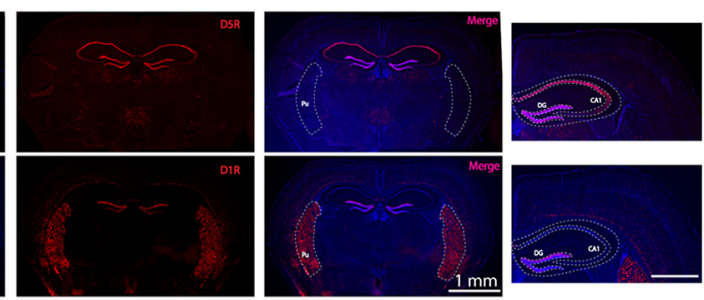

B

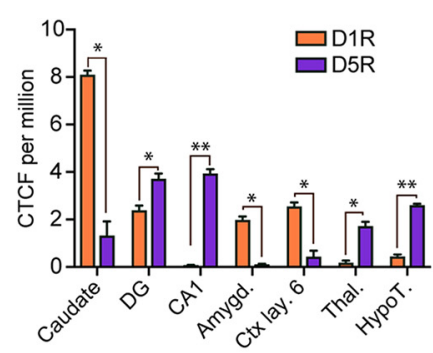

D

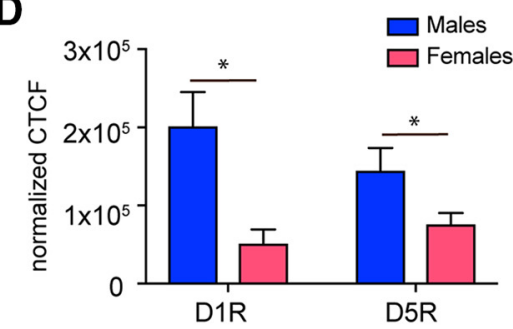

E

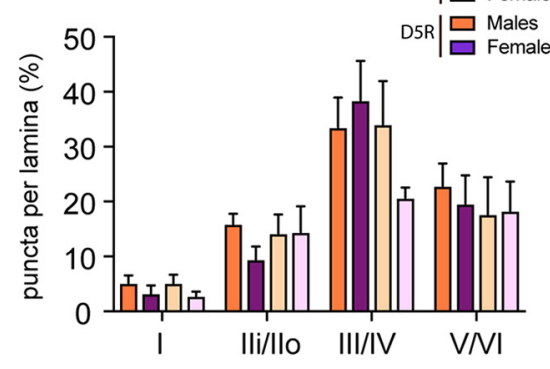

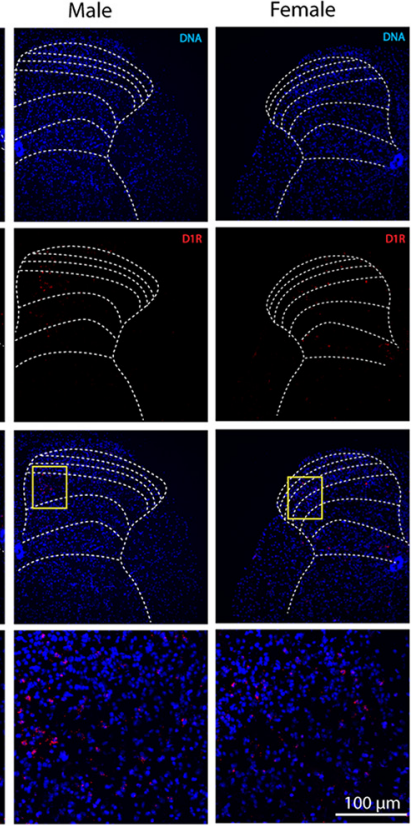

Figure 7. D1R and D5R mRNAs are highly expressed in the lamina III/IV of the dorsal horn of the spinal cord. $\boldsymbol{A}$, Image showing the pattern of D1R and D5R mRNA expression in the brain. $\boldsymbol{B}$, D1R mRNA expression is significantly higher in the caudate compared with D5R mRNA, whereas D5R mRNA is predominantly expressed in CA1 where D1R mRNA is almost completely absent. Images are representative of 3 mice. C, Images showing the pattern of expression of the D1R and D5R mRNAs in the spinal cord. D, CTCF analysis demonstrates a significant higher level of D1R and D5R mRNAs in the spinal cord of male compared with female mice. $E$, Moreover, D1R and D5R are highly enriched in the lamina III/IV of the spinal cord in male and female mice. $N=3$ mice per group. ${ }^{*} p<0.05$ ( $t$ test with correction for multiple comparisons). ${ }^{* *} p<0.01$ ( $t$ test with correction for multiple comparisons).

receptors wherein D5Rs have no apparent effect in female mice. Our previous study showed that spinal injection of a D1LR antagonist SCH23390 reversed hyperalgesic priming in male and female WT mice (J. Y. Kim et al., 2015). We hypothesized that female mice may rely more on spinal D1Rs instead of D5Rs in hyperalgesic priming. To test this, we gave carrageenan-primed female DRD5KO mice (Fig. 6I) intrathecal injections of SCH23390, a D1LR antagonist, or vehicle. The D1LR antagonist blocked $\mathrm{PGE}_{2}$ induced mechanical hypersensitivity in primed, female $D R D 5 K O$ mice at $3 \mathrm{~h}(p<0.05$, WT vs D5KO) but not at $24 \mathrm{~h}(p=0.063$, WT vs D5KO) (Fig. 6J), suggesting that D1Rs contribute to hyperalgesic priming in female mice.

\section{D1R and D5R mRNAs are highly expressed in lumbar DRGs} as well as in lamina III of the spinal cord

D1Rs are among the most abundant receptors expressed in the brain, especially in the basal ganglia, the amygdala, and layer 6 of the cortex (Weiner et al., 1991). On the other hand, D5Rs are restricted to specific subregions, such as CA1 of the hippocampus and some nuclei in the hypothalamus (www.gensat.org). Because D1R and D5R mRNAs share $>80 \%$ sequence homology within their highly conserved seven transmembrane spanning domains and display $50 \%$ overall homology at the amino acid level (Sidhu, 1998), we tested whether the in situ probes we used were able to selectively recognize either subtype of receptor mRNA without cross-reactivity. We found high levels of D1R mRNA expression in the caudate, whereas D5R mRNA was expressed at a significantly lower level (caudate: $p<0.05 \mathrm{D} 1 \mathrm{R}$ vs D5R) (Fig. $7 A, B$ ). Conversely, D5R mRNA was highly enriched in CA1 hippocampus as shown previously (Sariñana and Tonegawa, 2016), whereas D1R mRNA was not detected (CA1: $p<0.01$, D1R vs D5R) (Fig. 7A,B). We then sought to investigate whether there was a difference in the level of expression of D1R and D5R between males and females and where these receptor mRNAs were expressed in the adult dorsal horn of the spinal cord. CTCF was used to quantify the intensity of the signal (McCloy et al., 2014). We found that the level of D1R (D1R: $p<0.05$, males vs females) and D5R (D5R: $p<0.05$, males vs females) mRNA was significantly higher in male mice compared with females (Fig. 7C,D). We then tested whether D1R and D5R mRNAs could be differentially expressed in specific lamina of the spinal cord. Our findings indicate that, in males and females, D1R and D5R mRNA is primarily enriched in lamina III of the spinal cord (Fig. $7 E$ ), a region that is populated by a large number of GABAergic interneurons.

Given that we observed some differences in acute pain sensitivity in male DRD5KO mice, we also assessed D1R and D5R mRNA expression in the DRG. Both D1R and D5R mRNAs were found in DRG neurons (Fig. 8A). Interestingly, the overall ex- 
A
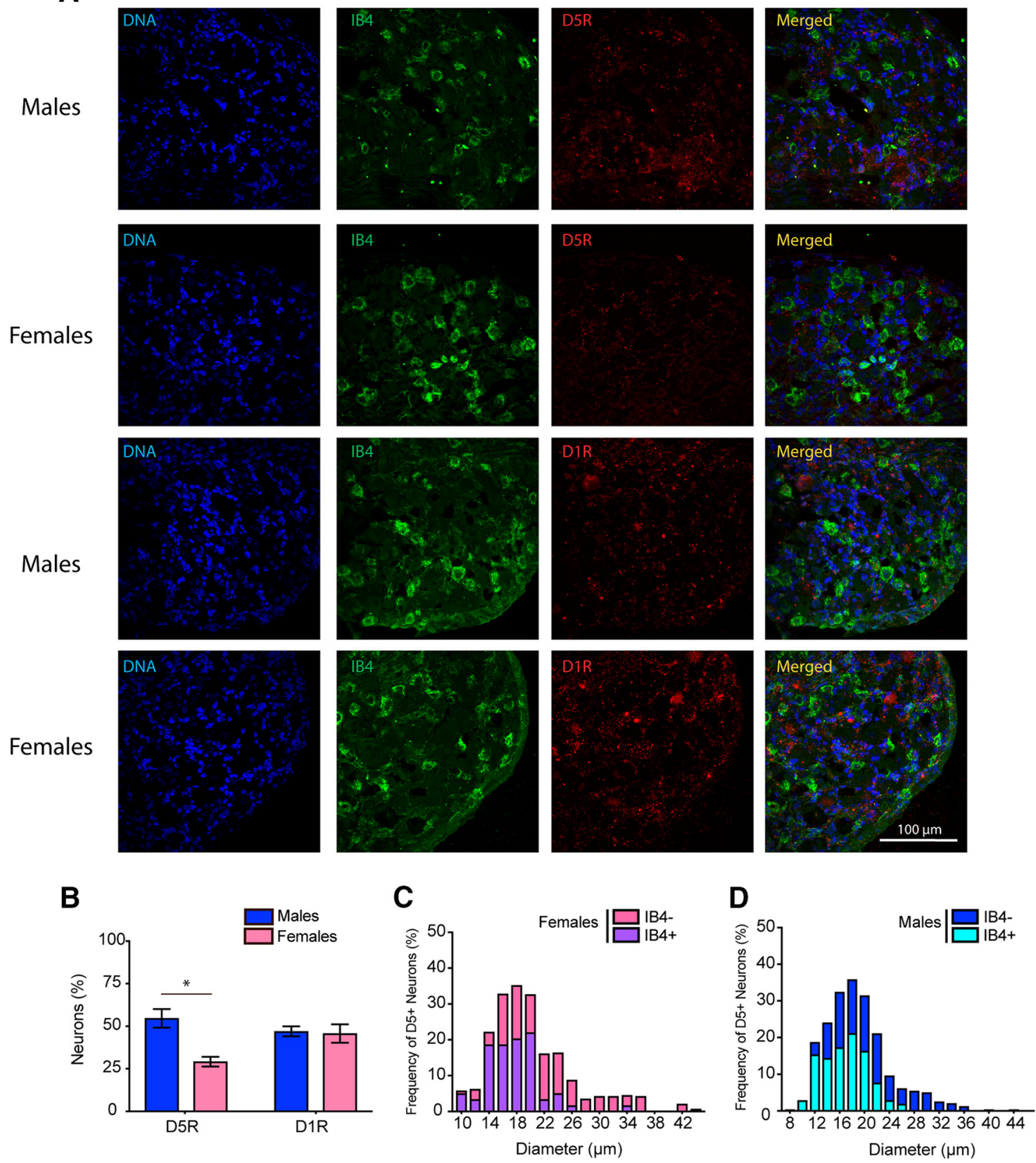

Figure 8. Differential expression of D5R mRNA in lumbar DRGs of male and female mice. $A$, Images represent the expression of D1R and D5R mRNAs in female and male lumbar DRGs. $\boldsymbol{B}$, Histogram represents the percentage of DRG neurons that are positive for D1R and D5R mRNA. Images are representative of 4 or 5 mice per group. $C$, Histogram showing the relative frequency of D5R mRNA-positive neurons as a function of the diameter of female lumbar DRG neurons. D, Histogram showing the relative frequency of D5R mRNA-positive neurons as a function of the diameter of neurons in male lumbar DRGs. $N=4$ or 5 mice per group. ${ }^{*} p<0.05$ ( $t$ test with correction for multiple comparisons).

pression level for D5R was reduced in female compared with male mice (D5R: $p<0.01$, males vs females), whereas D1R mRNA expression was equal between sexes (D1R: $p=0.82$, males vs females) (Fig. 8B). In male and female mice, D1R and D5R mRNA expression was mostly found in small-diameter neurons with some enrichment seen in IB4 ${ }^{+}$neurons, suggesting a high level of expression in nonpeptidergic C-fibers (Fig. 8C). The decreased expression of D5R mRNA found in female mice was largely accounted for by decreased expression in small-diameter, IB4-negative nociceptors that are mostly of the peptidergic class (Fig. 8D). This finding is consistent with the observed difference in baseline heat sensitivity between male and female DRD5KO mice being explained by differences in expression in the peptidergic population (Mogil et al., 2005).

D1RLR agonist induces c-fos expression in GABAergic neurons located in lamina III of the spinal cord of BDNF-primed mice

Our previous findings show that, although GABA-AR agonists and positive allosteric modulators reduce mechanical hypersensitivity to an acute injury, they fail to do so in animals with BDNF-induced hyperalgesic priming. In contrast, GABA-AR antagonism promotes antinociception and a reduction in facial grimacing in primed mice (J. Y. Kim et al., 2016). We used c-fos 
expression as an indirect marker of neuronal activity to identify whether a specific subset of dorsal horn neurons could be activated following D1LR agonist treatment in primed mice. We observed a significant increase of c-fos-positive neurons in lamina III and IV in male BDNF-primed mice treated with a D1LR agonist ( $p<0.001$, BDNF vs vehicle) (Fig. 9A,B), but there were no changes in other areas of the spinal cord. Laminae I-III of the spinal dorsal horn contain many inhibitory interneurons that use GABA and/or glycine as a neurotransmitter. Quantitative studies in the rat have shown that inhibitory interneurons account for $25 \%-40 \%$ of all neurons in this region (Todd, 2010). The lamina III and IV induction of c-fos by the D1LR agonist in BDNFprimed mice is consistent with our observation of strong D1R and D5R mRNA expression in this lamina of the dorsal horn. To test whether D1LR agonist-induced mechanical hypersensitivity in primed mice could be dependent on the GABAergic system, we first spinally injected the GABA-AR antagonist gabazine in naive animals and observed a strong mechanical hypersensitivity at $3 \mathrm{~h}$ ( $p<0.01$, vehicle vs gabazine) (Fig. 9C). In contrast, we observed that an acute intrathecal injection of gabazine was able to block D1LR agonist-induced mechanical hypersensitivity at $3 \mathrm{~h}(p<$ 0.001, vehicle vs gabazine) in BDNF-primed mice (Fig. $9 D$ ). This suggests that DA and GABAergic function are linked in the production of mechanical hypersensitivity specifically in primed mice. Inhibitory interneurons are found throughout the dorsal horn but are enriched in specific lamina, such as lamina II and III, where they coexpress an increasing well-understood number of marker peptides or calcium-binding proteins (Peirs and Seal, 2016). Somatostatin is a neuropeptide in inhibitory interneurons from lamina I to lamina III (Polgár et al., 2013), calretinin is calcium-binding protein that is mainly expressed in lamina II interneurons (Peirs et al., 2015), and PAX2 is a transcription factor expressed exclusively by GABAergic interneurons (Larsson, 2017). We used all of these markers, along with TRPV1 as a marker of peptidergic afferent endings, to gain insight into the dorsal horn neurons that express c-fos in primed animals stimulated with a D1LR agonist. Our findings show that $45 \%$ of the $\mathrm{c}$-fos-positive neurons are located in lamina innervated by TRPV1 afferents (Fig. 9E), indicating that a significant proportion of c-fos-positive neurons receive inputs from peptidergic neurons. A total of $22 \%$ of the c-fos-positive neurons express calretinin in lamina II (Fig. 9F), 27\% express somatostatin (Fig. $9 G$ ), and 30\% express PAX2 in lamina II-III (Fig. 9H). These findings indicate that many of the c-fos-positive neurons stimulated in primed animals are likely GABAergic neurons, but a substantial portion cannot be clearly identified by these established markers.

\section{Discussion}

Our work supports the following primary conclusions: (1) spinal DA projections play a critical role in BDNF-induced and other forms of hyperalgesic priming in male and female mice; (2) male, but not female, DRD5KO mice display decreased basal heat sensitivity and decreased responsiveness to irritant injection but have normal mechanical sensitivity; (3) spinal D5Rs play a key role in IL-6, BDNF, and carrageenan-induced hyperalgesic priming in male, but not female, mice; (4) D5R mRNA expression is higher in male than female mice in the spinal cord and DRG and is enriched in lamina III and IV neurons of the spinal cord; and (5) analysis of neurons activated by D1LRs in primed mice suggests engagement of a deep dorsal horn neuron circuit that includes GABAergic neurons. Collectively, our experiments further substantiate DA as a key regulator of spinal nociceptive plasticity, especially as pain becomes chronic, and indicate a novel role for D5Rs in pain with a surprisingly profound sexual dimorphism in mice.

The diencephalic A11 system provides the only known DA innervation of the spinal cord and has been implicated in pain modulation (Charbit et al., 2009; J. Y. Kim et al., 2015), spinal locomotor networks (Sharples et al., 2014), and restless legs syndrome (Clemens et al., 2006). Two recent studies have shed light on the diversity of neurons in the hypothalamus that project to the spinal cord; albeit the studies were performed in different species. A study in rat described three types of hypothalamospinal neurons, each having a specific neurochemical profile, which may suggest distinct functional roles in different sensory or motor modalities (Ozawa et al., 2017). As an example of this, a recent study in zebrafish identified the posterior tubercular DA system as an evolutionarily ancient, sensory-driven system in which anatomically and neurochemically distinct subpopulations are organized according to sensory stimuli modalities, and specific subgroups of these DA neurons regulate their activity levels according to sensory stimulus intensities (Reinig et al., 2017). Another interesting feature of A11 DA neurons is that previous investigations have not detected DAT or aromatic amino acid decarboxylase mRNAs in A11 (Koblinger et al., 2014), suggesting that A11 DA neurons may actually release L-Dopa rather than DA (Barraud et al., 2010). However, our current data, our previous findings (J. Y. Kim et al., 2015), and the work of other groups demonstrate that intrathecal 6-OHDA lesions A11 neurons and decreases DA levels in the spinal cord (Zhao et al., 2007). We observed DAT mRNA in the spinal cord. Some of this mRNA is likely contributed by a population of intrinsic dorsal horn neurons that express DAT, but some may also be contributed by DAT mRNA found in the terminals of projection neurons from the A11. This possibility could explain the lesion of these neurons by spinal 6-OHDA.

The above-mentioned issues about the neurochemical phenotype of A11 neurons that project to the spinal cord aside, our findings show that a spinally directed DA lesion reverses the presence of hyperalgesic priming across a broad variety of priming stimuli (J. Y. Kim et al., 2015) in male and female mice, and blockade of D1LRs leads to transient inhibition of neuropathic allodynia in the SNI model of neuropathic pain. This latter effect is consistent with previous findings showing that an inhibition of A11 neurons using a local infusion of a D2LR agonist completely blocked mechanical hypersensitivity in the rat spinal nerve ligation model (Wei et al., 2009). It is also aligned with other studies showing a strong A11 projection to the medullary dorsal horn (Abdallah et al., 2013) wherein inactivation of A11 neurons using local infusion of a GABA-AR agonist or lesioning A11 neurons inhibits trigeminal pain behavior (Abdallah et al., 2015). While our data, as well as these previous studies, provide strong support for A11 DA neurons in a pronociceptive role in pain modulation, our work also raises the possibility that an intrinsic population of neurons that express DAT mRNA may play a previously unrecognized role in spinal nociceptive circuitry. It will be interesting to use modern genetic tools to study both of these populations of neurons.

A primary goal of the experiments described here was to test the hypothesis that D5Rs play a critical role in pain modulation. Our previous findings indicate a critical function for D1LR receptors in plasticity underlying hyperalgesic priming (J. Y. Kim et al., 2015), and it is well known that DA plays a key role in modulation of synaptic plasticity throughout the CNS, primarily through a postsynaptic action on D1LR receptors (Hansen and 
A

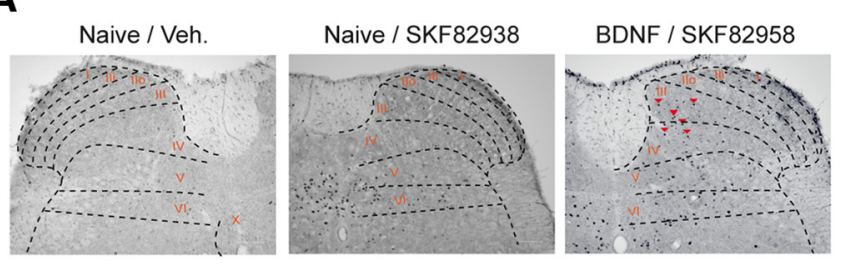

B

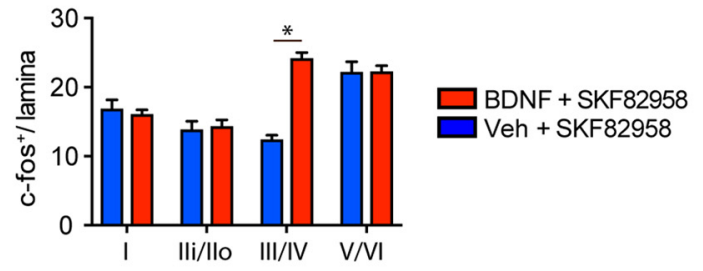

C

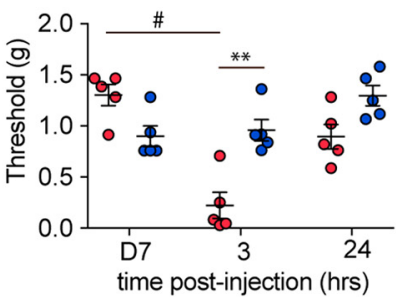

Veh/ Gbz $150 \mathrm{ng}$

$\bigcirc$ Veh/ Veh
D

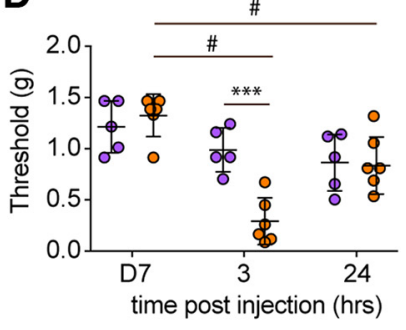

O BDNF / SKF $4.1 \mu \mathrm{g} / \mathrm{Veh}$

BDNF/SKF $4.1 \mu \mathrm{g} / \mathrm{Gbz} 150 \mathrm{ng}$

E
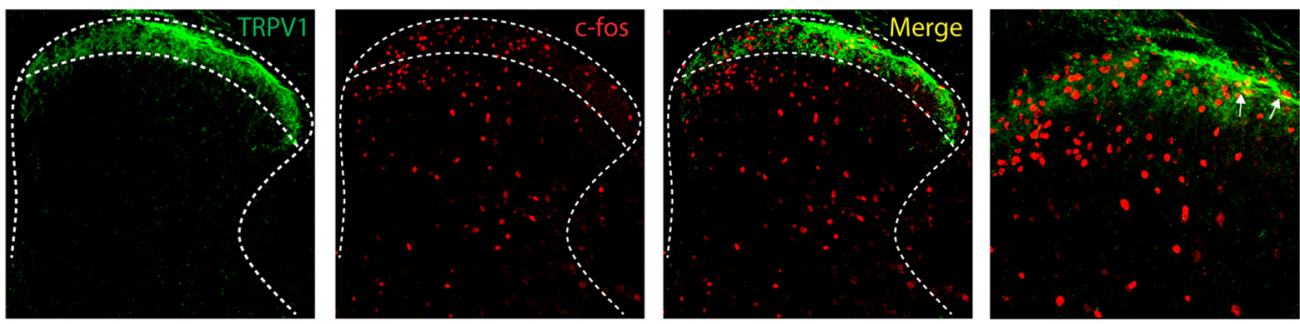

TRPV1/c-fos: $14 \%$ c-fos/TRPV1: $45 \%$

F
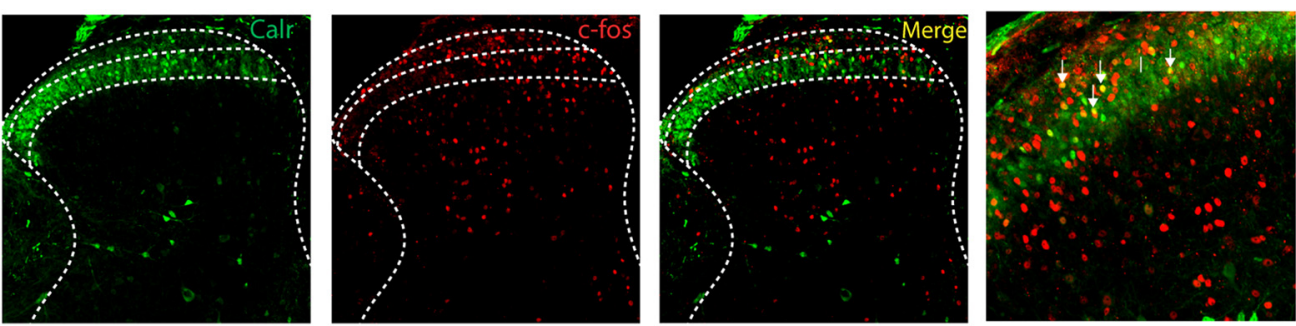

G
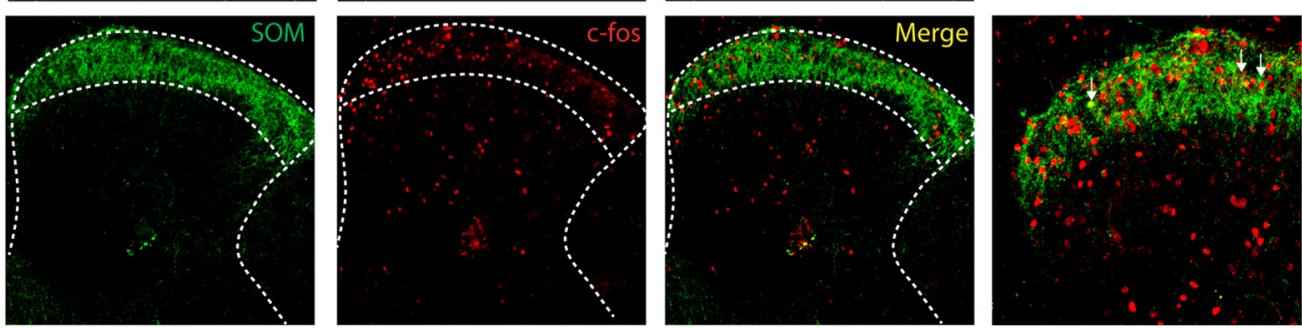

H
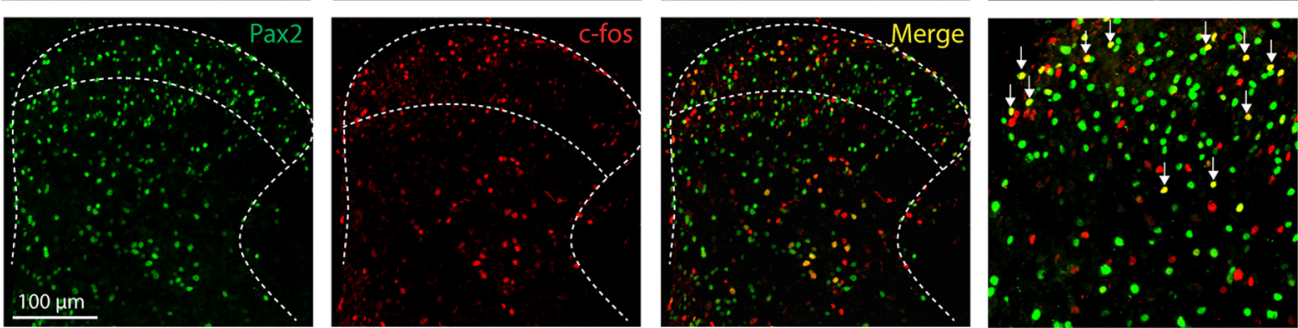

SOM/c-fos: $6 \%$ c-fos/SOM: $27 \%$

Calr/c-fos: $20 \%$

c-fos/Calr: $22 \%$

Pax2/c-fos: $22 \%$

c-fos/Pax2: $30 \%$

Figure 9. D1LR activation promotes hyperalgesic priming via a GABAergic mechanism in the lamina III of the spinal cord. $A$, Coronal section of the spinal cord showing an increase of c-fos-positive neurons in lamina III/IV. B, Spinal injection of the D1LR agonist SKF82958 in BDNF-primed mice induces a significant increase of c-fos-positive neurons in the lamina III and IV. $N=3$ mice per group. C, Intrathecal injection of the GABA-AR antagonist gabazine produces a strong mechanical hypersensitivity in nonprimed mice that lasts for $24 \mathrm{~h}$, whereas the D1LR agonist has no effect. $N=5$ or 6 mice per group. $\boldsymbol{D}$, Intrathecal injection of gabazine in BDNF-primed mice completely reverses D1LR agonist-induced mechanical hypersensitivity. $N=5$ or 6 mice per group. ${ }^{* *} p<0.01$, WT versus DRD5KO (two-way ANOVA with Bonferroni post hoc test). ${ }^{* * *} p<0.001$, WT versus DRD5KO (two-way ANOVA with Bonferroni post hoc test). ${ }^{*} p<0.05$, compared with baseline (two-way ANOVA with Bonferroni post hoc test). $\boldsymbol{E}$, In BDNF-primed mice, $45 \%$ of the c-fos-immunoreactive neurons colocalize with TRPV1 afferent terminal staining in lamina I/II ( $N=3 / \mathrm{group}) . \boldsymbol{F}, \mathrm{A}$ total of $20 \%$ of the $c$-fos-immunoreactive neurons also express calretinin in lamina II ( $N=3 /$ group). $\mathbf{G}$, In lamina I-III, $27 \%$ of the $c$-fos-immunoreactive neurons express somatostatin ( $N=3 /$ group). $\boldsymbol{H}$, Finally, in BDNF-primed mice, $30 \%$ of the $c$-fos neurons express PAX2, a marker of GABAergic interneurons. ${ }^{*} p<0.05$ (two-way ANOVA with Bonferroni post hoc test). ${ }^{* * *} p<0.001$ (two-way ANOVA with Bonferroni post hoc test). 
Manahan-Vaughan, 2014). However, few studies have attempted to delineate between the contributions of D1Rs and D5Rs to these effects, and no studies in the pain field have done this. In testing our primary hypothesis, we found a strong role for D5Rs in pain modulation in the spinal cord and DRG with a surprisingly profound sex difference. For instance, we found that male, but not female, DRD5KO mice show decreased noxious heat sensitivity. Previous studies show that D1R and D5R are both expressed in peripheral nociceptors (Xie et al., 1998) as well as in the dorsal horn of the spinal cord (Zhu et al., 2007). Indeed, it has been shown that activation of D1LRs leads to trans-activation of TRPV1 (Lee et al., 2015), whereas another study demonstrated sensitization of TRPV1 (Chakraborty et al., 2016). Given our current findings, it is highly likely that this effect is actually mediated by the D5R and likely occurs specifically in males. This is consistent with our observation that D5R mRNA is more highly expressed in peptidergic neurons in males than females because these neurons are known to mediate heat sensitivity in mice. Interestingly, mice deficient for the D3R, a G $\alpha_{\mathrm{i}}$ coupled-receptor, exhibit thermal hypersensitivity (Keeler et al., 2012) in a sexdependent manner (Liu et al., 2017), suggesting that DA plays a critical role in setting noxious heat sensitivity.

We also found a sexually dimorphic effect of D5Rs in the spinal cord. We observed deficits in hyperalgesic priming specifically in male DRD5KO mice and an increased level of D5R expression in male versus female mice. A very recent study also observed a sexual dimorphism in D1R and D2R expression in the frontal cortex of young rats (Orendain-Jaime et al., 2016), suggesting that sex differences in the DA receptor system may be found throughout the CNS. Although there is a sexual dimorphism in the role of the D5R in our observations, we emphasize that D1Rs appear to fulfill the role that D5Rs assume in male mice when similar experiments are conducted in female mice. Therefore, the spinal DA system plays a critical role in pain modulation in both sexes, but the receptor dependence of this effect varies by sex of the mouse. It remains to be seen whether this effect is conserved in other species.

The current study shows that primed animals exhibit a specific pattern of c-fos expression when treated with a D1LR agonist and many of these neurons are found in the deep dorsal horn (lamina III-IV). This overlaps with the mRNA expression pattern for D1R and D5R and suggests that many of those c-fos-positive neurons might express one or both of those receptors. Technical limitations of the in situ hybridization approach prohibited us from examining overlap of the mRNAs for these receptors with c-fos staining. Nevertheless, we show that c-fos-positive neurons coexpress a variety of markers, including the calcium binding protein, calretinin, which is expressed by excitatory or inhibitory interneurons (Smith et al., 2016), and 30\% of the c-fos-positive neurons coexpress PAX2, a transcription factor known to be expressed exclusively in GABAergic interneurons in the murine spinal cord (Larsson, 2017). Hence, our findings point to an important modulation of deep dorsal horn GABAergic interneurons by DA in primed mice. This conclusion is supported by our behavioral observation that spinal GABA-AR antagonism in primed animals induced antinociception, at a dose that is pronociceptive in nonprimed animals.

How might DA neurons be linked to GABAergic neurons in the deep dorsal horn? Neuroligin 2 is a synaptic adhesion molecule thought to be exclusively expressed within inhibitory synapses (Varoqueaux et al., 2004). However, recent findings reported that dopamine synapses are neurochemically mismatched contacts containing neuroligin 2 formed between dopaminergic presynaptic and
GABAergic postsynaptic neurons (Uchigashima et al., 2016). Interestingly, neuroligin 2 expressed at the GABAergic postsynaptic structure controls striatal synapse formation by giving competitive advantage to heterologous dopamine synapses over conventional GABAergic synapses. We previously showed that hyperalgesic priming drives an increase in neuroligin 2 expression in the spinal cord and that the behavioral maintenance of hyperalgesic priming can be completely reversed by an intrathecal injection of a neuroligin-2 inhibitory peptide (J. Y. Kim et al., 2016). We therefore speculate that the increase in neuroligin 2 expression in the spinal cord that is linked to chronic pain may drive the formation of neurochemically mismatched synapses that create a pathological link between two neurotransmitter systems in the deep dorsal horn.

\section{References}

Abdallah K, Artola A, Monconduit L, Dallel R, Luccarini P (2013) Bilateral descending hypothalamic projections to the spinal trigeminal nucleus caudalis in rats. PLoS One 8:e73022. CrossRef Medline

Abdallah K, Monconduit L, Artola A, Luccarini P, Dallel R (2015) GABAAergic inhibition or dopamine denervation of the A11 hypothalamic nucleus induces trigeminal analgesia. Pain 156:644-655. CrossRef Medline

Aira Z, Barrenetxea T, Buesa I, García Del Caño G, Azkue JJ (2016a) Dopamine D1-like receptors regulate constitutive, -opioid receptor-mediated repression of use-dependent synaptic plasticity in dorsal horn neurons: more harm than good? J Neurosci 36:5661-5673. CrossRef Medline

Aira Z, Barrenetxea T, Buesa I, Martínez E, Azkue JJ (2016b) Spinal D1-like dopamine receptors modulate NMDA receptor-induced hyperexcitability and NR1 subunit phosphorylation at serine 889 . Neurosci Lett 618: 152-158. CrossRef Medline

Asiedu MN, Tillu DV, Melemedjian OK, Shy A, Sanoja R, Bodell B, Ghosh S, Porreca F, Price TJ (2011) Spinal protein kinase M underlies the maintenance mechanism of persistent nociceptive sensitization. J Neurosci 31:6646-6653. CrossRef Medline

Bäckman CM, Malik N, Zhang Y, Shan L, Grinberg A, Hoffer BJ, Westphal H, Tomac AC (2006) Characterization of a mouse strain expressing Cre recombinase from the $3^{\prime}$ untranslated region of the dopamine transporter locus. Genesis 44:383-390. CrossRef Medline

Barraud Q, Obeid I, Aubert I, Barrière G, Contamin H, McGuire S, Ravenscroft P, Porras G, Tison F, Bezard E, Ghorayeb I (2010) Neuroanatomical study of the A11 diencephalospinal pathway in the non-human primate. PLoS One 5:e13306. CrossRef Medline

Beaulieu JM, Gainetdinov RR (2011) The physiology, signaling, and pharmacology of dopamine receptors. Pharmacol Rev 63:182-217. CrossRef Medline

Bhattacharyya S, Borthakur A, Anbazhagan AN, Katyal S, Dudeja PK, Tobacman JK (2011) Specific effects of BCL10 Serine mutations on phosphorylations in canonical and noncanonical pathways of NF- $\kappa \mathrm{B}$ activation following carrageenan. Am J Physiol Gastrointest Liver Physiol 301:G475G486. CrossRef Medline

Bolte S, Cordelières FP (2006) A guided tour into subcellular colocalization analysis in light microscopy. J Microsc 224:213-232. CrossRef Medline

Burgos-Vega CC, Quigley LD, Avona A, Price T, Dussor G (2016) Dural stimulation in rats causes BDNF-dependent priming to subthreshold stimuli including a migraine trigger. Pain 157:2722-2730. CrossRef Medline

Chakraborty S, Rebecchi M, Kaczocha M, Puopolo M (2016) Dopamine modulation of transient receptor potential vanilloid type 1 (TRPV1) receptor in dorsal root ganglia neurons. J Physiol 594:1627-1642. CrossRef Medline

Chang PC, Pollema-Mays SL, Centeno MV, Procissi D, Contini M, Baria AT, Martina M, Apkarian AV (2014) Role of nucleus accumbens in neuropathic pain: linked multi-scale evidence in the rat transitioning to neuropathic pain. Pain 155:1128-1139. CrossRef Medline

Chaplan SR, Bach FW, Pogrel JW, Chung JM, Yaksh TL (1994) Quantitative assessment of tactile allodynia in the rat paw. J Neurosci Methods 53:5563. CrossRef Medline

Charbit AR, Akerman S, Goadsby PJ (2009) Comparison of the effects of central and peripheral dopamine receptor activation on evoked firing in 
the trigeminocervical complex. J Pharmacol Exp Ther 331:752-763. CrossRef Medline

Charbit AR, Akerman S, Goadsby PJ (2011) Trigeminocervical complex responses after lesioning dopaminergic A11 nucleus are modified by dopamine and serotonin mechanisms. Pain 152:2365-2376. CrossRef Medline

Clemens S, Rye D, Hochman S (2006) Restless legs syndrome: revisiting the dopamine hypothesis from the spinal cord perspective. Neurology 67: 125-130. CrossRef Medline

Decosterd I, Woolf CJ (2000) Spared nerve injury: an animal model of persistent peripheral neuropathic pain. Pain 87:149-158. CrossRef Medline

Dolique T, Favereaux A, Roca-Lapirot O, Roques V, Léger C, Landry M, Nagy F (2013) Unexpected association of the "inhibitory" neuroligin 2 with excitatory PSD95 in neuropathic pain. Pain 154:2529-2546. CrossRef Medline

Dubois A, Savasta M, Curet O, Scatton B (1986) Autoradiographic distribution of the D1 agonist $\left[{ }^{3} \mathrm{H}\right] \mathrm{SKF} 38393$, in the rat brain and spinal cord: comparison with the distribution of D2 dopamine receptors. Neuroscience 19:125-137. CrossRef Medline

Hansen N, Manahan-Vaughan D (2014) Dopamine D1/D5 receptors mediate informational saliency that promotes persistent hippocampal longterm plasticity. Cereb Cortex 24:845-858. CrossRef Medline

Hollon TR, Bek MJ, Lachowicz JE, Ariano MA, Mezey E, Ramachandran R, Wersinger SR, Soares-da-Silva P, Liu ZF, Grinberg A, Drago J, Young WS 3rd, Westphal H, Jose PA, Sibley DR (2002) Mice lacking D5 dopamine receptors have increased sympathetic tone and are hypertensive. J Neurosci 22:10801-10810. Medline

Keeler BE, Baran CA, Brewer KL, Clemens S (2012) Increased excitability of spinal pain reflexes and altered frequency-dependent modulation in the dopamine D3-receptor knockout mouse. Exp Neurol 238:273-283. CrossRef Medline

Kim JI, Ganesan S, Luo SX, Wu YW, Park E, Huang EJ, Chen L, Ding JB (2015) Aldehyde dehydrogenase 1a1 mediates a GABA synthesis pathway in midbrain dopaminergic neurons. Science 350:102-106. CrossRef Medline

Kim JY, Tillu DV, Quinn TL, Mejia GL, Shy A, Asiedu MN, Murad E, Schumann AP, Totsch SK, Sorge RE, Mantyh PW, Dussor G, Price TJ (2015) Spinal dopaminergic projections control the transition to pathological pain plasticity via a D1/D5-mediated mechanism. J Neurosci 35:63076317. CrossRef Medline

Kim JY, Megat S, Moy JK, Asiedu MN, Mejia GL, Vagner J, Price TJ (2016) Neuroligin-2 regulates spinal GABAergic plasticity in hyperalgesic priming, a model of the transition from acute to chronic pain. Pain 157:13141324. CrossRef Medline

Koblinger K, Füzesi T, Ejdrygiewicz J, Krajacic A, Bains JS, Whelan PJ (2014) Characterization of A11 neurons projecting to the spinal cord of mice. PLoS One 9:e109636. CrossRef Medline

Langford DJ, Bailey AL, Chanda ML, Clarke SE, Drummond TE, Echols S, Glick S, Ingrao J, Klassen-Ross T, Lacroix-Fralish ML, Matsumiya L, Sorge RE, Sotocinal SG, Tabaka JM, Wong D, van den Maagdenberg AM, Ferrari MD, Craig KD, Mogil JS (2010) Coding of facial expressions of pain in the laboratory mouse. Nat Methods 7:447-449. CrossRef Medline

Larsson M (2017) Pax2 is persistently expressed by GABAergic neurons throughout the adult rat dorsal horn. Neurosci Lett 638:96-101. CrossRef Medline

Lee DW, Cho PS, Lee HK, Lee SH, Jung SJ, Oh SB (2015) Trans-activation of TRPV1 by D1R in mouse dorsal root ganglion neurons. Biochem Biophys Res Commun 465:832-837. CrossRef Medline

Levant B, McCarson KE (2001) D(3) dopamine receptors in rat spinal cord: implications for sensory and motor function. Neurosci Lett 303:9-12. CrossRef Medline

Li Q, Lau A, Morris TJ, Guo L, Fordyce CB, Stanley EF (2004) A syntaxin 1, Galpha(o), and N-type calcium channel complex at a presynaptic nerve terminal: analysis by quantitative immunocolocalization. J Neurosci 24: 4070-4081. CrossRef Medline

Liu P, Xing B, Chu Z, Liu F, Lei G, Zhu L, Gao Y, Chen T, Dang YH (2016) Dopamine D3 receptor knockout mice exhibit abnormal nociception in a sex-different manner. J Neurosci Res 95:1438-1445. CrossRef Medline

López-Avila A, Coffeen U, Ortega-Legaspi JM, del Angel R, Pellicer F (2004) Dopamine and NMDA systems modulate long-term nociception in the rat anterior cingulate cortex. Pain 111:136-143. CrossRef Medline
McCloy RA, Rogers S, Caldon CE, Lorca T, Castro A, Burgess A (2014) Partial inhibition of Cdk1 in G2 phase overrides the SAC and decouples mitotic events. Cell Cycle 13:1400-1412. CrossRef Medline

Melemedjian OK, Tillu DV, Asiedu MN, Mandell EK, Moy JK, Blute VM, Taylor CJ, Ghosh S, Price TJ (2013) BDNF regulates atypical PKC at spinal synapses to initiate and maintain a centralized chronic pain state. Mol Pain 9:12. CrossRef Medline

Mogil JS, Miermeister F, Seifert F, Strasburg K, Zimmermann K, Reinold H, Austin JS, Bernardini N, Chesler EJ, Hofmann HA, Hordo C, Messlinger K, Nemmani KV, Rankin AL, Ritchie J, Siegling A, Smith SB, Sotocinal S, Vater A, Lehto SG, et al. (2005) Variable sensitivity to noxious heat is mediated by differential expression of the CGRP gene. Proc Natl Acad Sci U S A 102:12938-12943. CrossRef Medline

Moy JK, Khoutorsky A, Asiedu MN, Black BJ, Kuhn JL, Barragán-Iglesias P, Megat S, Burton MD, Burgos-Vega CC, Melemedjian OK, Boitano S, Vagner J, Gkogkas CG, Pancrazio JJ, Mogil JS, Dussor G, Sonenberg N, Price TJ (2017) The MNK-eIF4E signaling axis contributes to injuryinduced nociceptive plasticity and the development of chronic pain. J Neurosci 37 :7481-7499.

Neve KA, Seamans JK, Trantham-Davidson H (2004) Dopamine receptor signaling. J Recept Signal Transduct Res 24:165-205. CrossRef Medline

Orendain-Jaime EN, Ortega-Ibarra JM, López-Pérez SJ (2016) Evidence of sexual dimorphism in D1 and D2 dopaminergic receptors expression in frontal cortex and striatum of young rats. Neurochem Int 100:62-66. CrossRef Medline

Ossipov MH, Dussor GO, Porreca F (2010) Central modulation of pain. J Clin Invest 120:3779-3787. CrossRef Medline

Ozawa H, Yamaguchi T, Hamaguchi S, Yamaguchi S, Ueda S (2017) Three types of A11 neurons project to the rat spinal cord. Neurochem Res 42: 2142-2153. CrossRef Medline

Peirs C, Seal RP (2016) Neural circuits for pain: recent advances and current views. Science 354:578-584. CrossRef Medline

Peirs C, Williams SP, Zhao X, Walsh CE, Gedeon JY, Cagle NE, Goldring AC, Hioki H, Liu Z, Marell PS, Seal RP (2015) Dorsal horn circuits for persistent mechanical pain. Neuron 87:797-812. CrossRef Medline

Polgár E, Durrieux C, Hughes DI, Todd AJ (2013) A quantitative study of inhibitory interneurons in laminae I-III of the mouse spinal dorsal horn. PLoS One 8:e78309. CrossRef Medline

Price TJ, Flores CM (2007) Critical evaluation of the colocalization between calcitonin gene-related peptide, substance $\mathrm{P}$, transient receptor potential vanilloid subfamily type 1 immunoreactivities, and isolectin B4 binding in primary afferent neurons of the rat and mouse. J Pain 8:263-272. CrossRef Medline

Reinig S, Driever W, Arrenberg AB (2017) The descending diencephalic dopamine system is tuned to sensory stimuli. Curr Biol 27:318-333. CrossRef Medline

Sanchez BM, Lesch M, Brammer D, Bove SE, Thiel M, Kilgore KS (2008) Use of a portable thermal imaging unit as a rapid, quantitative method of evaluating inflammation and experimental arthritis. J Pharmacol Toxicol Methods 57:169-175. CrossRef Medline

Sariñana J, Tonegawa S (2016) Differentiation of forebrain and hippocampal dopamine 1-class receptors, D1R and D5R, in spatial learning and memory. Hippocampus 26:76-86. CrossRef Medline

Sawynok J, Reid A, Nance D (1991) Spinal antinociception by adenosine analogs and morphine after intrathecal administration of the neurotoxins capsaicin, 6-hydroxydopamine and 5,7-dihydroxytryptamine. J Pharmacol Exp Ther 258:370-380. Medline

Schambra UB, Duncan GE, Breese GR, Fornaretto MG, Caron MG, Fremeau RT Jr (1994) Ontogeny of D1a and D2 dopamine receptor subtypes in rat brain using in situ hybridization and receptor binding. Neuroscience 62:65-85. CrossRef Medline

Sharples SA, Koblinger K, Humphreys JM, Whelan PJ (2014) Dopamine: a parallel pathway for the modulation of spinal locomotor networks. Front Neural Circuits 8:55. CrossRef Medline

Sidhu A (1998) Coupling of D1 and D5 dopamine receptors to multiple G proteins. Mol Neurobiol 16:125-134. CrossRef Medline

Skagerberg G, Lindvall O (1985) Organization of diencephalic dopamine neurones projecting to the spinal cord in the rat. Brain Res 342:340-351. CrossRef Medline

Smith KM, Boyle KA, Mustapa M, Jobling P, Callister RJ, Hughes DI, Graham BA (2016) Distinct forms of synaptic inhibition and neuromodulation 
regulate calretinin-positive neuron excitability in the spinal cord dorsal horn. Neuroscience 326:10-21. CrossRef Medline

Taniguchi W, Nakatsuka T, Miyazaki N, Yamada H, Takeda D, Fujita T, Kumamoto E, Yoshida M (2011) In vivo patch-clamp analysis of dopaminergic antinociceptive actions on substantia gelatinosa neurons in the spinal cord. Pain 152:95-105. CrossRef Medline

Todd AJ (2010) Neuronal circuitry for pain processing in the dorsal horn. Nat Rev Neurosci 11:823-836. CrossRef Medline

Uchigashima M, Ohtsuka T, Kobayashi K, Watanabe M (2016) Dopamine synapse is a neuroligin-2-mediated contact between dopaminergic presynaptic and GABAergic postsynaptic structures. Proc Natl Acad Sci U S A 113:4206-4211. CrossRef Medline

Varoqueaux F, Jamain S, Brose N (2004) Neuroligin 2 is exclusively localized to inhibitory synapses. Eur J Cell Biol 83:449-456. CrossRef Medline

Watson C, Paxinos G, Kayalioglu G, Heise C (2009) Atlas of the mouse spinal cord. In: The spinal cord, pp 308-379. San Diego, CA: Elsevier Academic Press.

Wei H, Viisanen H, Pertovaara A (2009) Descending modulation of neuropathic hypersensitivity by dopamine D2 receptors in or adjacent to the hypothalamic A11 cell group. Pharmacol Res 59:355-363. CrossRef Medline

Weiner DM, Levey AI, Sunahara RK, Niznik HB, O’Dowd BF, Seeman P, Brann MR (1991) D1 and D2 dopamine receptor mRNA in rat brain. Proc Natl Acad Sci U S A 88:1859-1863. CrossRef Medline

Xie GX, Jones K, Peroutka SJ, Palmer PP (1998) Detection of mRNAs and alternatively spliced transcripts of dopamine receptors in rat peripheral sensory and sympathetic ganglia. Brain Res 785:129-135. CrossRef Medline

Yang HW, Zhou LJ, Hu NW, Xin WJ, Liu XG (2005) Activation of spinal d1/d5 receptors induces late-phase LTP of C-fiber-evoked field potentials in rat spinal dorsal horn. J Neurophysiol 94:961-967. CrossRef Medline

Yokoyama C, Okamura H, Nakajima T, Taguchi J, Ibata Y (1994) Autoradiographic distribution of $\left[{ }^{3} \mathrm{H}\right] \mathrm{YM}-09151-2$, a high-affinity and selective antagonist ligand for the dopamine D2 receptor group, in the rat brain and spinal cord. J Comp Neurol 344:121-136. CrossRef Medline

Zhao H, Zhu W, Pan T, Xie W, Zhang A, Ondo WG, Le W (2007) Spinal cord dopamine receptor expression and function in mice with 6-OHDA lesion of the A11 nucleus and dietary iron deprivation. J Neurosci Res 85:1065-1076. CrossRef Medline

Zhou P, Zhang Y, Ma Q, Gu F, Day DS, He A, Zhou B, Li J, Stevens SM, Romo $\mathrm{D}, \mathrm{Pu}$ WT (2013) Interrogating translational efficiency and lineagespecific transcriptomes using ribosome affinity purification. Proc Natl Acad Sci U S A 110:15395-15400. CrossRef Medline

Zhu H, Clemens S, Sawchuk M, Hochman S (2007) Expression and distribution of all dopamine receptor subtypes (D1-D5) in the mouse lumbar spinal cord: a real-time polymerase chain reaction and non-autoradiographic in situ hybridization study. Neuroscience 149:885-897. CrossRef Medline

Zhu H, Clemens S, Sawchuk M, Hochman S (2008) Unaltered D1, D2, D4, and D5 dopamine receptor mRNA expression and distribution in the spinal cord of the D3 receptor knockout mouse. J Comp Physiol A Neuroethol Sens Neural Behav Physiol 194:957-962. CrossRef Medline 